\title{
Design and Implementation of a Virtual Laboratory for Physics Subjects in Moroccan Universities
}

\author{
Khadija El Kharki $^{1}$ (D), Khalid Berrada ${ }^{1, *(D)}$ and Daniel Burgos ${ }^{2, *(D)}$ \\ 1 Trans ERIE-Faculty of Sciences Semlalia, Cadi Ayyad University, Marrakech 40000, Morocco; \\ khadijaelkharki.tr@gmail.com \\ 2 Research Institute for Innovation \& Technology in Education (UNIR iTED), Universidad Internacional de \\ La Rioja (UNIR), 26006 Logroño, Spain \\ * Correspondence: berrada@uca.ac.ma (K.B.); daniel.burgos@unir.net (D.B.); \\ Tel.: +212-6-7009-9167 (K.B.); +34-91-567-43-91 (D.B.)
}

Citation: El Kharki, K.; Berrada, K.;

Burgos, D. Design and

Implementation of a Virtual Laboratory for Physics Subjects in Moroccan Universities. Sustainability 2021, 13, 3711. https://doi.org/ $10.3390 /$ su13073711

Academic Editor: Changhyun Roh

Received: 15 January 2021

Accepted: 23 March 2021

Published: 26 March 2021

Publisher's Note: MDPI stays neutral with regard to jurisdictional claims in published maps and institutional affiliations.

Copyright: (c) 2021 by the authors. Licensee MDPI, Basel, Switzerland. This article is an open access article distributed under the terms and conditions of the Creative Commons Attribution (CC BY) license (https:// creativecommons.org/licenses/by/ $4.0 /)$.

\begin{abstract}
Laboratory experimentation has a vital role in science education. With the potential offered by information and communication technologies for the educational domain, virtual laboratories have emerged as a valuable alternative to face-to-face, hands-on laboratories. Moreover, the possibility of virtual laboratories opens new perspectives for higher education sustainability. They are a perfect approach for training learners to understand scientific principles in many fields of science by offering them the possibility to illustrate the scientific phenomena through automated and virtual practical activities that employ computer simulation. In this work, we present the use of computer simulation combined with the JavaScript programming language for the development of a low-cost virtual laboratory integrated into an interactive learning environment based on the Moodle platform. The methodology was based on the instructional design model ADDIE (Analysis, Design, Development, Implementation, and Evaluation), which structures the development planning of online teaching resources in different stages (analysis, design, development, implementation, and evaluation). The virtual laboratory was developed by Moroccan universities, with the help of European partners, and it was implemented in the 12 science faculties in Morocco. It presents a great choice for supporting laboratory activities for learners in the first year of their bachelor's degree program. This virtual laboratory includes 12 virtual practical activities mapped to the physics curriculum, and they can be operated via the Internet on computers. The proposed virtual learning environment was evaluated by teachers and learners from the science faculties. The obtained results, together with similar findings from other studies, indicate the positive impact of the use of a virtual laboratory on learning outcomes, and support the adoption of the proposed learning environment in laboratory educational procedures as an alternative to physical laboratories.
\end{abstract}

Keywords: education technology; virtual laboratory; simulation; JavaScript programming language; e-learning platform; hands-on learning; practical work; experiments; science teaching; higher education; physics; sustainable scientific laboratories; EXPERES project

\section{Introduction}

To achieve sustainable development goals, the world requires young people who are skillful and keen on science, and who view science as their future career field [1-3]. Learning science is therefore essential for today's learners. At a learner's level, this helps them to participate as informed and active members of society, and the scientific ways of thinking and skills help them in making decisions based on evidence [4] and also in improving their problem-solving abilities [5]. More specifically, applying science to our daily life needs both theory and a hands-on practicum. While the former lends itself to classroom learning, the latter can only be learned and practiced in a physical [6] or digital laboratory. Indeed, the value of laboratory experiments for science learning is generally recognized [7], as they are an important element in the educational process [8,9] and science 
cannot be taught meaningfully to learners without practical laboratory experience. Science laboratories can help learners to acquire a positive attitude toward science if they enable learners to be involved in active and successful laboratory activities [10]. Policy makers worldwide recommend including scientific investigations in courses for learners of all ages. Indeed, investigations afford opportunities for learners to interact directly with the material world by using the tools, models, and theories of science [11]. Likewise, activities in a science laboratory provide learners with opportunities to construct their knowledge by experimenting [12], permitting them to combine their perception of theory with laboratory practice [13], and enabling them to develop their skills [14].

For a decade now, Morocco, like other nations, has been experiencing a growing demand for access to higher education. Morocco has 12 public universities (Cadi Ayyad University (UCA), Abdelmalek Essaadi University (UAE), Mohammed V University (UM5), Hassan 1st University (UH1), Hassan II University (UH2), Mohammed 1er University (UMP), Chouaib Doukkali University (UCD), Moulay Ismail University (UMI), Sultan Moulay Sliman University (USMS), Ibn Zohr University (UIZ), Ibn Tofail University (UIT), Sidi Mohammed Ben Abdellah University (USMBA)) spread over the national territory. These universities are becoming unable to keep pace with the growing number of learners and the increasing demand for access to higher education. In addition, despite significant efforts to improve and increase the absorption capacity of universities, for example, by expanding the faculties infrastructure, these efforts are still unable to keep up with the continuous high increase in the number of learners.

Multiple educational initiatives [15-22] based on the integration and use of new technological advances that support the educational processes are taking place in the current teaching and learning approaches, to meeting this growing demand for access to higher education and to encourage greater learner participation and promote innovative and open teaching practices in Moroccan universities. This aim is well highlighted in goal 4 of the United Nations objectives for sustainable development, but these initiatives aim particularly at improving the quality and accessibility of theoretical courses.

Science education is based on the learner's experimentation in scientific laboratories, where theoretical principles are verified, and the teaching is given a practical orientation [23]. In science faculties, several thousand learners participate in practical laboratory activities in the science disciplines (physics, chemistry, biology, geology, and mathematics). Basically, physics is a science that is produced through observations, investigations, and experiments conducted by experts who develop laws, principles, concepts, and rules in the form of mathematical equations or statements [24]. Physics is commonly taught for all these majors in the first year of university. With the rapid increase of new learners enrolled each year since 2012 in the science faculties, in addition to (1) an increase in the number of laboratory groups; (2) the low number of laboratories at the faculties; (3) inadequate and insufficient scientific material; (4) deteriorated scientific equipment; (5) an insufficient number of supervisors in laboratories; (6) insufficient numbers of preparers and technicians; and (7) learner demotivation, it has become impossible for the educational and administrative staff in the physics departments at the 12 Moroccan universities to schedule and to continue providing physical laboratory practical activities for all learners enrolling in the physics courses of the first year.

Unfortunately, due to all those listed constraints, the Ministry of National Education, Professional Training, Higher Education, and Scientific Research has decided to eliminate the real practical laboratory activities for physics from the first year program for all science faculties. At the same time, it has been necessary to think about appropriate alternatives to provide training in the laboratory and to adopt digital contents and formats within didactic curricula for surmounting this situation. A solution to this issue can be found in the adoption of virtual laboratories, which would allow the creation of virtual practical activities that can simulate the processes and actions that take place in physical laboratories. This was our main goal in looking for sustainable solutions at Moroccan universities to the 
problems of massification and the inaccessibility of practical work after the decision of the ministry to remove it from the curricula for the first year.

While the influence of information technologies and the Internet on education has radically changed the laboratory science education landscape [25], a new form of the laboratory has emerged. Web-based experimentation or online experimentation promotes learner immersion in virtual environments, recreating the real experience. It is a broad concept that includes many online experimentation tools, such as virtual and remote laboratories, virtual reality, augmented reality, interactive videos, and serious games [26]. Furthermore, it is commonly accepted that digital tools such as interactive simulations or online laboratories can positively affect learner knowledge, skills, and attitudes $[27,28]$.

In our research work, we have an interest in the integration and use of virtual laboratories in scientific and technical education disciplines for many reasons; virtual laboratories help overcome the limitations of physical face-to-face laboratories, such as equipment accessibility, location, and other economic issues. In particular, virtual laboratories are an appropriate tool that can withstand massive access. Indeed, virtual laboratories are computer simulations that offer views and ways of working that are similar to traditional hands-on, face-to-face laboratories [29], and they are environments where learners can perform learning activities [30]. Also, virtual laboratories help learners to engage in their proactive learning process and improve their academic performance [31]. Nowadays, virtual laboratories have developed into interactive graphical online user interfaces in which simulated experiments can be carried out and where learners can manipulate the experiment's parameters and explore its evolution [32]. The experiments are completely web-based and provide online access. These interesting advantages over traditional handson, face-to-face laboratories and many other attractive gains were discussed in detail in a previous research publication [33].

In Moroccan science faculties, a major initiative that aims to introduce online simulationbased virtual laboratories into scientific teaching was conducted by the EXPERES project from 2016 to 2018. EXPERES (Information and Communication Technologies for Education applied to scientific experiments) is an Erasmus + CBHE project. A joint effort among 12 public universities and European partners from Spain and Finland has been the key solution to overcome the problem of practical work at Moroccan universities. Its main objective was the development and implementation of a virtual laboratory as an alternative solution to support the practical work of physics for the benefit of scientific learners in the first year of their bachelor's degree program. The EXPERES project was approved and supported by the Moroccan Ministry of National Education, Professional Training, Higher Education and Scientific Research and the Moroccan public universities, which were involved and engaged in the development of the digital content for the virtual practical learning environment $[33,34]$.

The purpose of this article is to present the EXPERES virtual laboratory developed using the JavaScript programming language and deployed by the Moodle platform. It also presents the tool used to create and develop scientific computer simulations. The rest of this paper is organized as follows: The Section 2 presents the usefulness of online scientific experimentations and laboratories for science education. The Section 3 describes the adoption of the ADDIE (Analysis, Design, Development, Implementation, and Evaluation) methodology for developing the virtual laboratory. The Section 4 presents a case study. The Section 5 outlines the results and feedback from teachers and learners. Finally, the Section 6 is dedicated to the conclusion.

\section{Online Scientific Experimentations and Laboratories}

\subsection{The Potential of Online Experimentation to Ensure Sustainability for Science Education}

Education presents a major point of the 2030 agenda for sustainable development, being both directly connected to the 17 goals of the agenda and at the core of sustainable development goal 4 , which aims to ensure inclusive and equitable quality education and promote lifelong learning opportunities for all [35]. In addition, the education system is 
the key instrument to achieve the United Nations 2030 agenda for sustainable development $[36,37]$. There is an accord that higher education institutions play an essential role in accomplishing sustainable development goals [2,38], while an inefficient educational system not only influences learners' learning but also impacts the entire society [39]. Educational technology and online learning have become the pillars of the education of the 21 st century and very particularly for ensuring the education for sustainability $[2,40]$. The development and use of open educational resources (OERs) have an important potential to expand access to learning, enhance the learning experience, and improve the quality of education [41,42]. The adoption of OER and open educational practices (OEPs) builds a sustainable education infrastructure that enhances education quality and offers good learning opportunities.

On the other hand, online laboratories provide great potential for conducting scientific investigations. In addition, online experimentations represented one of the latest pedagogical trends in the educational context during the last few years. They unite the educational benefits from learning-by-doing approaches with the advantages offered by the information and communication technologies (ICTs) for the educational domain [43]. Moreover, they have been adapted to science education as an effective tool for improving the learning quality and the teaching methodologies, enhancing the learning experiences, and increasing the learners' participation and motivation, in addition to expanding educational opportunities for more learners $[44,45]$. Also, online laboratories are a very useful tool to ensure educational continuity for laboratory activities in times of crisis when learners can no longer access the physical laboratory [46].

\subsection{Related Work}

Online experimentation is a large concept that covers many approaches and tools such as remote laboratories [47,48], virtual laboratories [49], virtual and augmented reality [50-54], gamification [55], and other technological tools.

To meet our need for an alternative solution to the elimination of traditional hands-on laboratory activities, we chose to develop a virtual laboratory, the reasons cited below justify this choice:

- Implementing a virtual laboratory is a low-cost solution, no equipment is needed for performing the experimentations, all the development work and the implementation are done by the computer;

- Deploying the virtual laboratory resources is guaranteed through using a Moodle platform;

- Performing practical activities through a virtual laboratory is a cheap and sustainable solution;

- Increasing the learners' motivation and their ability to self-study;

- Accessing the virtual laboratory by learners is allowed at all times and places; also, it supports the learners' simultaneous connections, which means that multiple learners can do the same experiment at the same time.

In this project, virtual laboratories are considered as OERs [18,56], and they are one of the most interesting OERs that might be offered for science education. Meanwhile, creating, developing, and sharing virtual laboratories are OEPs. These two important characteristics of virtual laboratories allow them to be considered as very powerful tools to address challenges related to ensuring sustainable science education. Another aspect of the sustainable goal of this project was its use during the COVID-19 pandemic, where engineering schools, faculties of sciences and technologies, normal high schools, and polydisciplinary faculties were adapting such online virtual practical work on their platform.

A virtual laboratory is an interactive practical environment where learners can conduct scientific simulated experiments [57]; in addition, they have the potential to enhance learners' skills, attitudes, and understanding of physics concepts. Many different empirical studies in different areas of science education have shown that the use of virtual laboratories enables learning results comparable to traditional hands-on laboratories [30,58-65]. Moreover, according to Salmerón-Manzano and Manzano-Agugliaro's study [57], they 
concluded that researches concerning virtual laboratories are being implemented as a model of teaching and learning with a great future within the university worldwide.

Likewise, learning topics related to theoretical concepts in physics require simulations to support learners' understanding; for this reason, virtual laboratories are widely used in learning physics [1,24]. Multiple pilot research projects have been carried out to develop examples of virtual laboratories that can be used for practical teaching of physics in higher education. De La Torre et al.'s study [32] revealed the positive impact of using the virtual laboratory and its Moodle deployment on the learners' learning. Billah and Widiyatmoko's study [66] confirmed that the contents of the virtual laboratory that provides theoretical material with pictures, animation, and videos let learners learn independently. This is because learners now tend to prefer things related to computers [67]. In Zhao et al.'s study [68], a virtual laboratory was designed to support and enrich the undergraduate learners' laboratory experience in addition to the existing physical laboratory; the learners considered that the virtual laboratory was very informative and useful. Studies $[69,70]$ revealed that the use of virtual laboratory media could improve the learners' conceptual understanding, as well as their problem-solving ability [71], and it enhances their creativity [72]. Jiménez et al.'s study [73] mentioned that virtual laboratories open new learning perspectives that cannot fully be explored in a traditional laboratory.

In addition, the immense boon of virtual laboratories was appreciated when the educational activities were affected due to lockdown related to the COVID-19 pandemic [46]. While the theory classes were conducted online, the educational institutions found it difficult to complete the syllabus concerning the laboratory experiments due to the closure of universities as well as conventional laboratories. Kapilan et al. [74] presented the exploitation of virtual laboratories based on simulation during the COVID-19 pandemic for providing learners of mechanical engineering education the opportunity to complete the planned laboratory experiments; the learners' feedback in this study indicated that the virtual laboratories helped them to understand the theoretical concepts, and they felt that it was necessary to introduce virtual laboratories into the engineering curriculum. GarcíaVela et al.'s study [75] recommended maintaining the use of the virtual spaces developed during the pandemic as a resource to reinforce the teaching and learning process.

Virtual laboratories are online education tools that bring a new dimension to learning science by using visualization techniques such as animation, simulation, and filmed videos $[31,76]$. They are a particular approach to hands-on laboratory experience employing computer-based simulations that focus on presenting views and ways of working that are similar to their physical counterparts [77]. They are used to attract learners' attention and sustain their motivation [78]. Furthermore, they present additional benefits such as supporting distance learning [79]. They are becoming essential components for e-learning environments, especially for scientific and technical education disciplines.

The use of interactive computer simulations in science education has been subjected to several studies $[60,64,80]$. In science education, the use of computer simulations plays a significant role in enriching teaching, making lectures more attractive to learners and helping them achieve a deeper comprehension of the scientific subjects $[81,82]$ by providing the learner a high level of interaction, active engagement and participation, immediate feedback, and repeated practice challenges [83]. Higher gains for learners using computer simulations than for those using only hands-on activities were also shown in a study on learning physics concepts [80]. The use of carefully designed computer simulations has the potential to result in more favorable attitudes toward science among learners [61]. Simulation is an educational approach to designing teaching and e-learning activities [83]. Computer simulations are programs that model aspects of real-world situations, they include mathematical models and they calculate the effects of certain inputs and select results accordingly [84]. They provide quantitative and hands-on experience for each experiment that supplements real laboratory practices and skills [31]. Simulation software has been increasingly used as an educational tool in recent decades [85]. The ongoing 
development of technology and programming languages has made simulation an advanced tool that reflects real situations with a high degree of precision [86].

\section{Materials and Methods}

Laboratory activities are an important pedagogical strategy for acquiring competencies in science education, making learners understand through a practical approach the theoretical topics taught in the classroom. However, due to various shortcomings of traditional laboratories, virtual laboratories have emerged as an alternative to the weakness of physical, face-to-face laboratories, and they are considered as one of the most attractive e-learning applications for higher education [57]. Furthermore, they have been proven to be a powerful tool to achieve sustainability in education.

Building a virtual laboratory for teaching and learning is a highly complicated process. Because experiments performed in traditional hands-on, face-to-face teaching laboratories are not easy to transfer to the online environment, several technicalities are needed to express the behavior of the phenomenon in computer form. Furthermore, these experiments often use scientific instruments and other specialized equipment. Their conception requires skills in diverse areas such as interaction design, visualization, and pedagogy, involving the design and production of texts, images, environments, and interactivity; their production requires programming and animation [30].

Developing an online virtual laboratory is an educational engineering project that requires defining a coherent and adapted strategy. To do that, we chose the ADDIE model (Figure 1) as the main design method. The ADDIE model is the most recognized model of educational engineering; more specifically, it is an instructional system design framework. ADDIE is a colloquial term used to describe a systematic approach to instructional development, virtually synonymous with instructional systems development [87]. The ADDIE model focuses on the process by listing the elements that must be taken into account when developing the educational content.

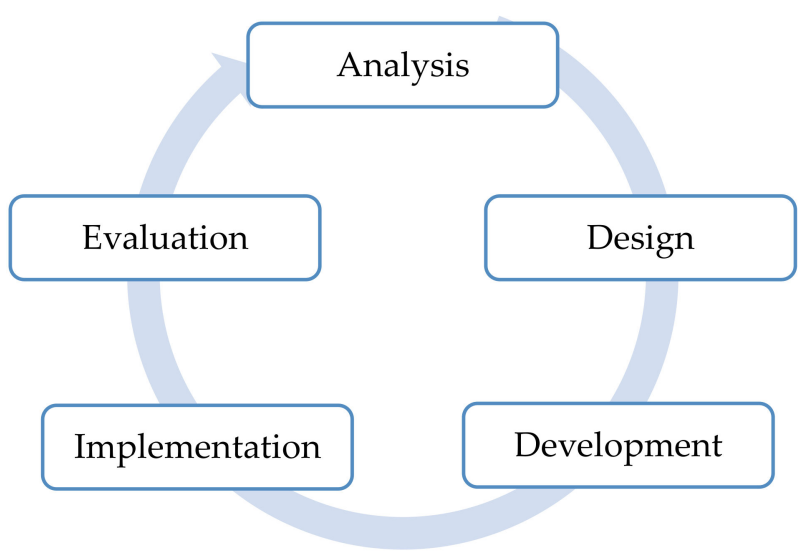

Figure 1. The ADDIE (Analysis, Design, Development, Implementation, and Evaluation) model.

ADDIE represents the five steps of analysis, design, development, implementation, and evaluation. The methodology adopted for developing such a virtual laboratory was based on the ADDIE model, as follows: (1) analysis: defining the subject, level, list of practical activities to elaborate; (2) design: elaborating the conceptualization and scripting sheets for all determined practical activities; (3) development: developing JavaScript programs for creating simulations, also producing supplementary resources for the laboratory environment; (4) implementation: putting a Moodle platform online and integrating the virtual simulations created and the resources produced; and (5) evaluation: evaluating the laboratory environment content and design for future improvement. The following paragraphs detail the development process, present the tools used, and justify their choices. 


\subsection{Analysis}

In the introduction, the reasons for choosing to implement a virtual laboratory for the physics subject were justified. Mechanics, thermodynamics, electricity, and optics are the physics program modules that are taught in the first year of university, so it was decided to reproduce the same three practical activities performed in a physical laboratory for each module as virtual activities, for a total of 12 activities (Figure 2). Work teams were created at the level of each university, each team was committed to the development of a virtual practical activity, following the actions and pre-planning established by the project steering committee in the work package.

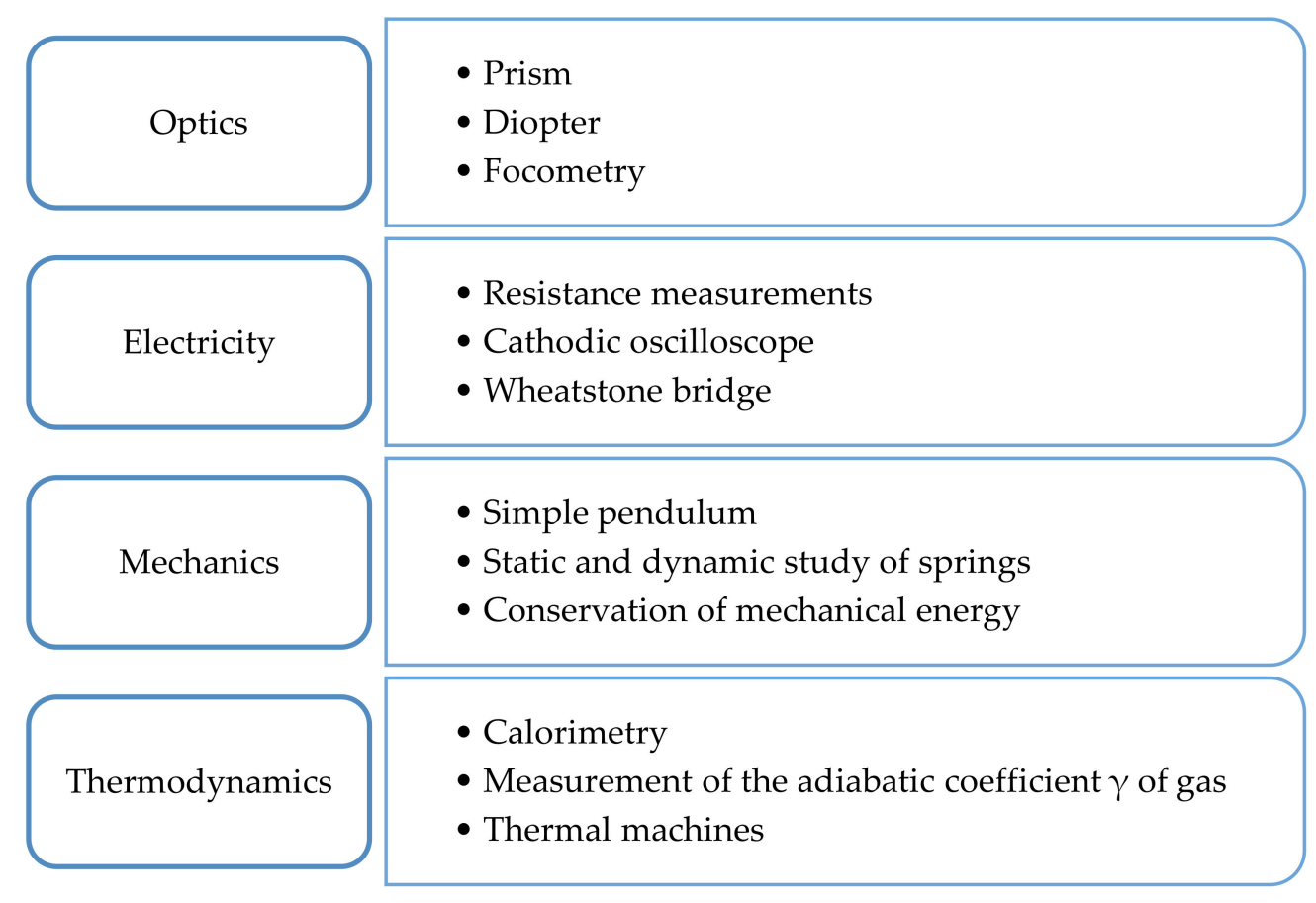

Figure 2. The 12 practical activities scheduled for the physics modules in the first year.

\subsection{Design}

For the development of each virtual practical activity, the preparation of conceptualization and scripting sheets was essential.

The conceptualization sheet (Figure 3a) described the learning activity in detail by defining the learning activities, the set of tasks proposed to learners, the objectives of the practical activity, and the educational resources to be used for performing the activity. Its creation required a very thorough knowledge of the practical activity in order to make a clear and detailed description of the pedagogical scenario, according to the definition of (1) context and pedagogical choice of the practical activity; (2) target level; (3) pedagogical objectives; (4) prerequisites; (5) content; (6) pedagogical resources and materials; (7) skills to be acquired by learners; and (8) assessment methods and tools.

The scripting sheet (Figure 3b) was prepared based on the conceptualization sheet. It consisted of writing a script that envisaged the realization of the learning sequences and the manipulation of graphic objects within a work environment according to a certain predefined order. Indeed, the objective of scripting is to identify learning sequences by cutting the content into sequences according to specific learning objectives. It also involves organizing resources and planning activities to prepare the order of different sequences or sub-activities for carrying out the proposed activity according to the experimental protocol. In general, the scripting of practical activities consists of the implementation of a coherent strategy integrating a certain number of pedagogical techniques and methods aimed at the 
exact formulation of the desired concept. The scripting sheet is fundamental to facilitating the programming stage and the development of simulations.

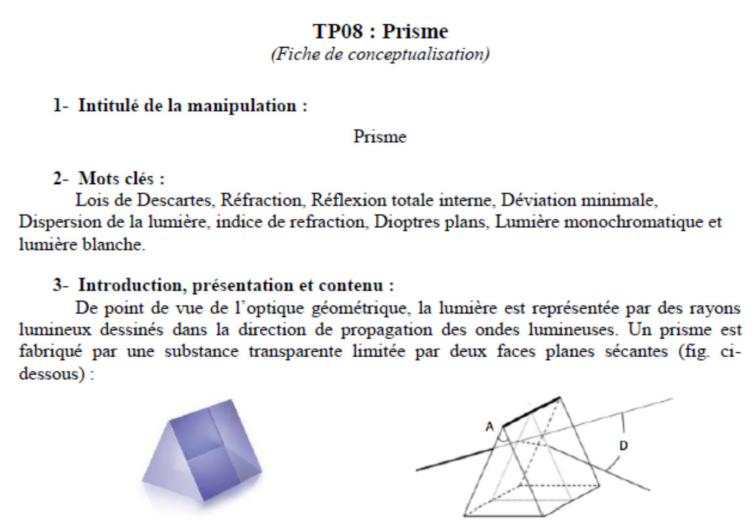

On étudiera la propagation d'un rayon lumineux à travers un prisme et les conditions d'émergence. De même on passera en revue la déviation et la dispersion de la lumière à travers un prisme. L'étude sera faite uniquement sur une section plane du prisme (confondue avec le plan d'incidence), où les lois de Snell-Descartes restent applicables. Ce TP sera accessible en ligne à travers une plateforme pédagogique offrant un maximum d'interactivité à l'étudiant qui pourrait réaliser lui même ses activités pratiques de laboratoire en mode virtuel. L'étudiant sera amené à vérifier les relations du prisme et comprendre les concepts de 4- vivaque géométrique.

TP de niveau première année universitaire (Semestres 1 et 2).

5- Pré requis

Connaissances de base

Nófins sur la propagation rectiligne de la lumière,

$\checkmark$ Lois de Descartes et leurs applications,

$\checkmark$ Définition d'une lumière monochromatique et d'une lumière blanche.

6- Objectifs pédagogiques:

$\checkmark$ Déterminer les équations du prisme

$\checkmark$ Etudier la déviation à travers un prisme,

(a)

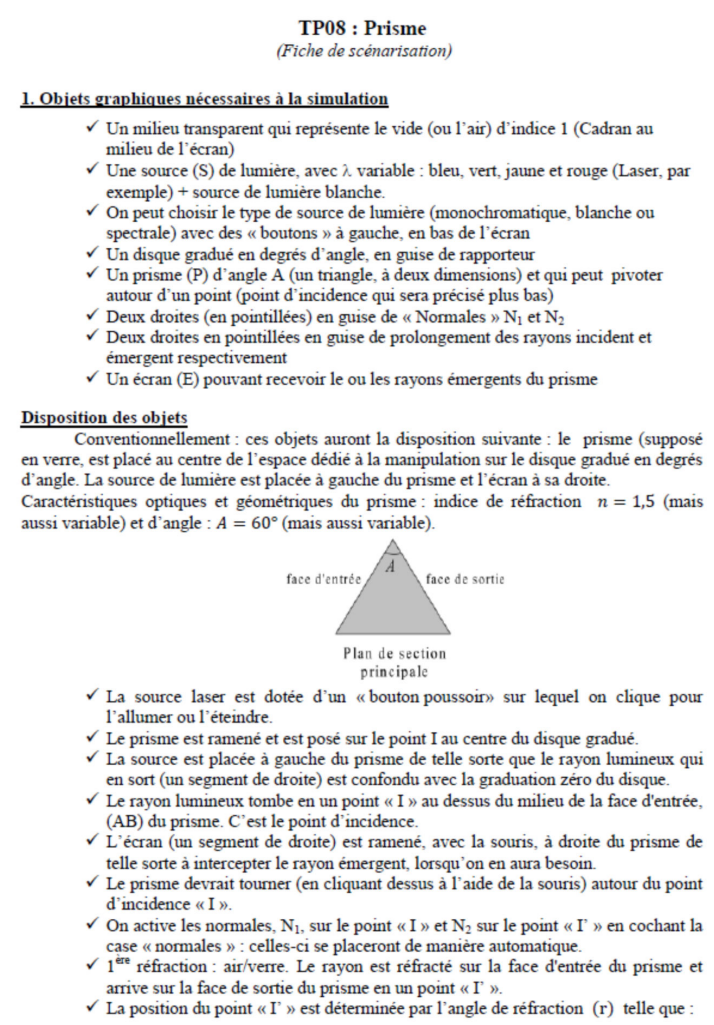

(b)

Figure 3. An example of the conceptualization and scripting sheets: (a) the conceptualization sheet; (b) the scripting sheet.

\subsection{Development}

Developing virtual laboratories from scratch requires an immense effort [32]. The use of Easy JavaScript Simulations (EJSS) [81,88] to create and develop virtual laboratories for science education helped to overcome those difficulties and obstacles. But extra effort was still needed to create a sophisticated, interactive graphical user interface and to develop innovative techno-pedagogical aspects allowing learners a new paradigm of learning practical work.

EJSS is an open-source software tool that was developed in Java and specially designed for the creation of scientific discrete computer simulations in JavaScript programming language for web-accessible online laboratories. EJSS helps to create and produce the simulations and allows users to concentrate most of their time on writing, refining, and improving the algorithms of the underlying scientific model (which is the real expertise), and on writing an additional JavaScript program to develop sophisticated and advanced simulations as required and according to the real needs for the hands-on experimentation, or to add other parameters to the primary simulation. By doing so, programmers can still obtain an independent, high performance, Internet-aware final product. The program provides simplified input forms that correspond to the common structure found in most simulations, so teachers need to provide the JavaScript code relevant to the model and design the user interface for the simulation, using high-level components. EJSS then generates all the code needed for the complete simulation, compiles it, and creates the extra material needed, such as a Hypertext Markup Language (HTML) page, to publish the simulation on the Internet.

Advanced simulations were created in two steps: the building of the model using the built-in simulation mechanism of EJSS, and the construction of the view to show the model 
state and its reactions to the changes made by learners. EJSS provided a simplified program structure, custom model tools (such as an advanced differential equation editor), and dragand-drop view elements that let teachers work at a high level of abstraction, thus speeding up the creation process. Teachers input the qualified information on the simulation such as math equations, the initial model state, the design of the learners' graphic interface, etc., and the program takes care of all the computer-related aspects of creating a finished, independent JavaScript applet.

Another important advantage of EJSS is that it offers hundreds of EJS simulations that can be freely downloaded, modified, and readjusted to create new simulations.

The decision to use JavaScript as a development language was justified by the fact that embedded JavaScript applets are supported and compatible with many web browsers, and that it is supported on several e-learning platforms. For example, JavaScript makes it possible to create JavaScript applications that can be added very easily to the Moodle platform. This means that EJSS, and the simulations created using it, can be used as independent programs under different operating systems, or be distributed via the Internet and run within HTML pages by the most popular web browsers.

Figure 4 below shows the EJSS development interface with an example of JavaScript code for creating the prism simulations that will be presented in the case study in the next section.

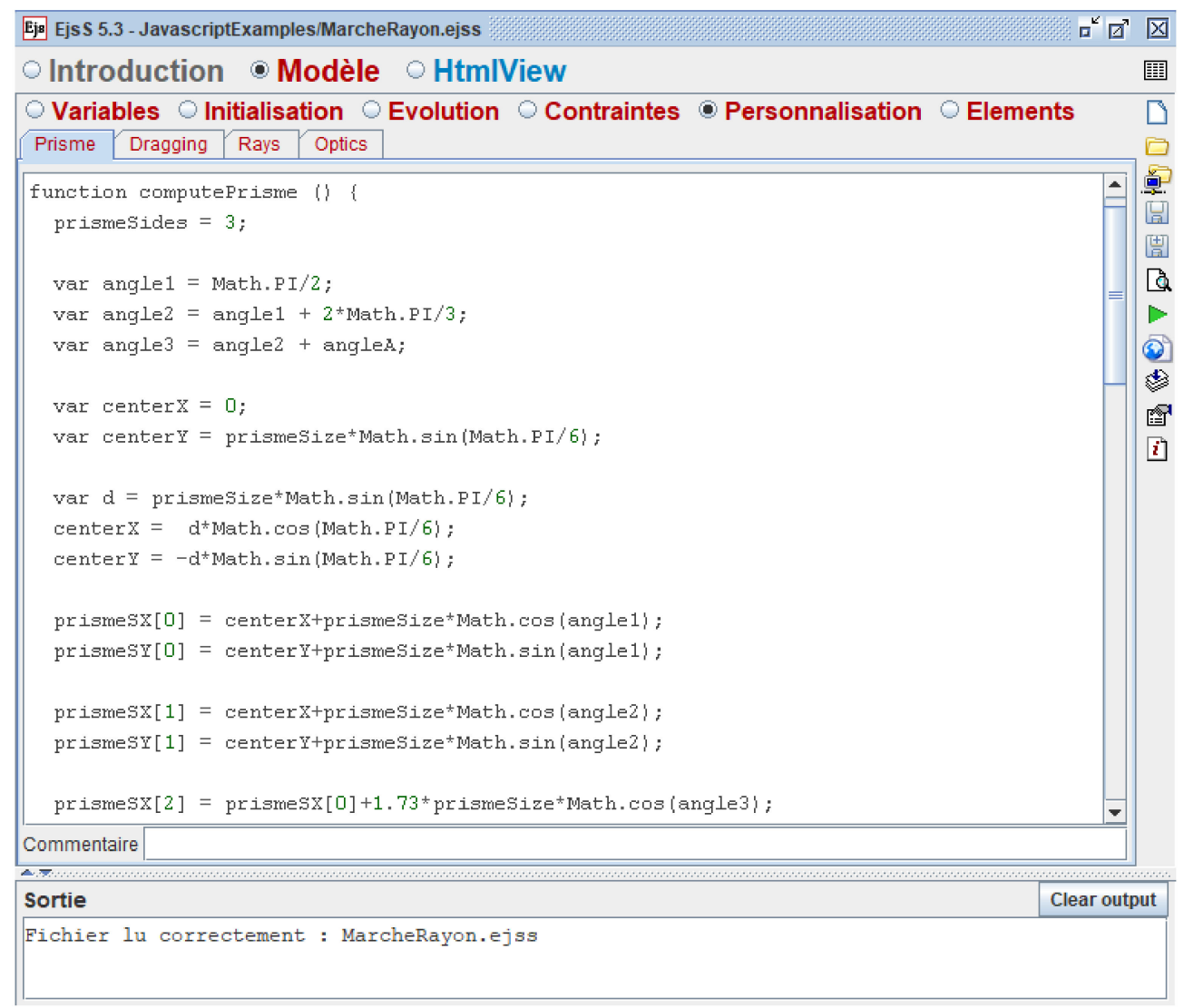

Figure 4. The Easy JavaScript Simulations (EJSS) development interface with an example of JavaScript code for creating the prism object.

The development of an effective virtual laboratory required the deployment of a series of simulations and other appropriate resources. In this step, in addition to the development of the virtual simulations for the 12 activities, other complementary resources were produced in order to provide a complete laboratory environment similar to the physical one: teasers and laboratory videos were filmed, assessment activities, multiplechoice questions (MCQs), simulation files, and theoretical resources were prepared. 
- The teaser presented the background, objectives, and the different parts of the practical activity;

- Laboratory video showed the hands-on activity performed in the physical laboratory with real materials and equipment;

- Theoretical resources offered a summary of the theoretical course and focused on the parts concerning the practical activity;

- MCQs provided learners the possibility to do a self-assessment of laws and equations presented in the theoretical course, which will be used in the practical activity;

- Simulation files included the experimental protocol, and the operating mode, for providing a laboratory working environment like to the real one;

- Assessment activity or the simulation report presented the tasks and exercises that the learner should answer during and after performing the practical activity.

\subsection{Implementation}

The decision to use the Moodle platform [89] as a learning environment to deploy the virtual laboratory was explained by the fact that Moodle is a learning management system (LMS) that supports the management, administration, documentation, tracking, and reporting of training programs, classrooms, and online events. Virtual laboratories take advantage of the Moodle platform capacity to support virtual interaction among learners and tutors through both synchronous and asynchronous collaboration tools. The deployment of the virtual laboratories inside the Moodle platform makes it possible for virtual simulations to be handled by multiple learners simultaneously and provides social contexts where learners interact with each other by the possible collaborative asynchronous and synchronous features such as chat and forums.

Furthermore, the Moodle platform helped to distribute all the convenient resources for a complete online experiment; it included a description of the phenomena under study and the task protocol that learners must follow to achieve the goals of the virtual practical activities. It provided possibilities for performing statistics and supervising the time spent working by learners in each activity.

Figure 5 below provides an overview of the Moodle activities and resources that can be used to display the virtual laboratory digital resources on the platform.

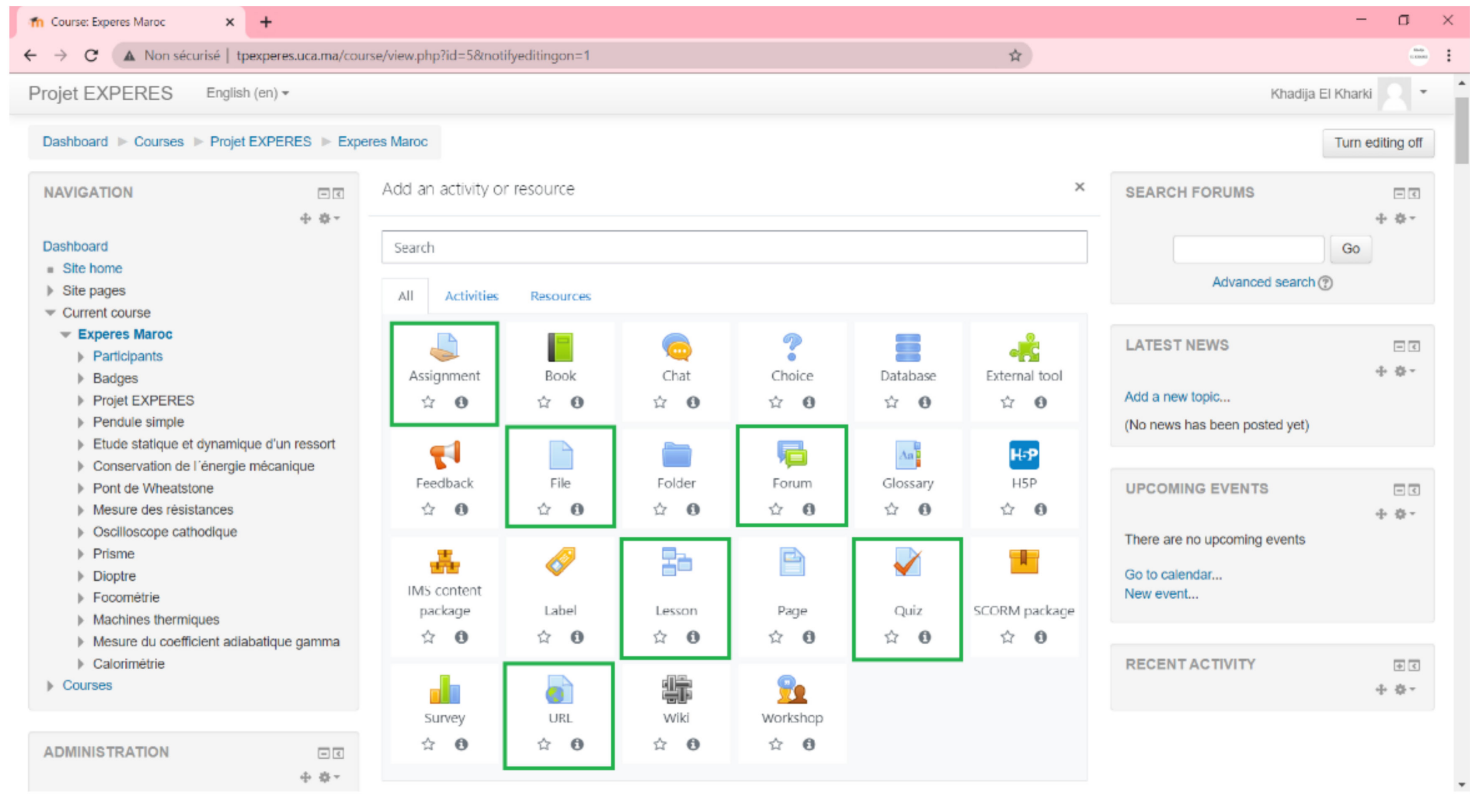

Figure 5. The Moodle activities and resources used for displaying the digital resources and contents on the platform.

For the integration of all the produced resources and contents of the virtual laboratory into the Moodle platform a course space was created. The activities and resources presented 
in the Table 1 below were used, adapted, and configured for displaying the digital resources of the virtual laboratory.

Table 1. Presentation of the Moodle activities and resources used to display the virtual laboratory digital resources and contents.

\begin{tabular}{cl}
\hline Moodle Activities and Resources & \multicolumn{1}{c}{ Description } \\
\hline Lesson & $\begin{array}{l}\text { The lesson activity module enables to delivery of the content and practice activities in exciting } \\
\text { and flexible ways. It is used to create a linear set of content pages or instructional activities } \\
\text { that offer a variety of paths or options for the learner. It offers the possibility to progress to the } \\
\text { next page, be taken back to a previous page, or be redirected down a different path entirely } \\
\text { according to the learner's answer or choice, and also on how the lesson activity } \\
\text { was developed. }\end{array}$ \\
\hline File & $\begin{array}{l}\text { The file module is used to display the simulation file created in the EJSS. It is used also to } \\
\text { provide the theoretical resources, the simulation operating mode, and the experimental } \\
\text { protocol in Word and Pdf format. }\end{array}$ \\
\hline URL & $\begin{array}{l}\text { The URL module is used to provide a web link to teasers and laboratory videos that were put } \\
\text { in a Google Drive repository. }\end{array}$ \\
\hline Quiz & $\begin{array}{l}\text { The quiz activity is used to create the MCQs for the self-assessment of some parts of the } \\
\text { theoretical course. }\end{array}$ \\
\hline Assignment & $\begin{array}{l}\text { The assignment activity module is used to collect the learner's simulation report by typing } \\
\text { the answers directly into the text editor and to provide grades and feedback. }\end{array}$ \\
\hline Forum & The forum activity module is used to enable learners to have asynchronous discussions. \\
\hline
\end{tabular}

Also, the virtual laboratory can be integrated into many LMSs. We chose the Moodle platform because it is more popular; also, learners as well teachers were very familiar with using it as an online learning environment.

The developed virtual laboratory architecture shown in Figure 6 was composed of two layers: (1) the server and (2) the user interface. The server placed in the university computer node was used to host the created Moodle platform and its resources. It allowed the interactions with these resources and handled the incoming requests from end-users. The user interface allowed learners and users in general to communicate and interact with the virtual laboratory deployed on the Moodle platform, to operate online through the Internet the laboratory simulation and the other resources, and also to perform laboratory virtual activities.
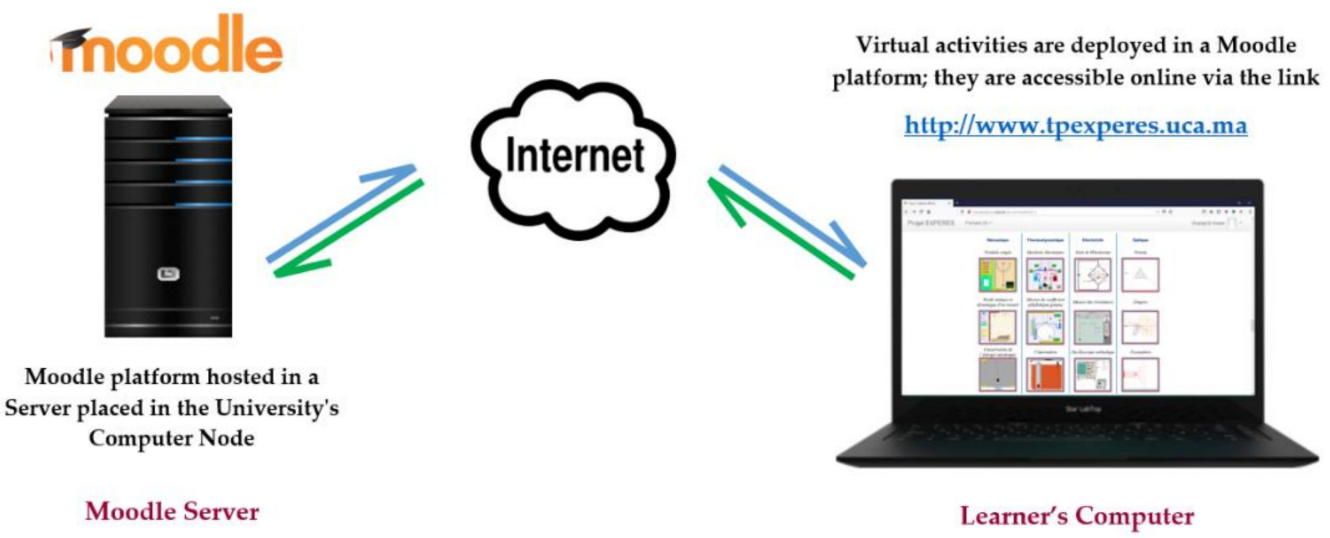

Figure 6. The architecture of the virtual laboratory deployed on the Moodle platform.

Accessing the virtual laboratory did not require any particular application or plug-in installed in the learners' computers, except a web browser, an Internet connection, and the authentication login and password to access the Moodle platform. 


\subsection{Evaluation}

To validate the created virtual learning environment, teachers and learners experimented with and tested the functioning of the developed simulation and activities. The remarks, feedback, and proposed suggestions were integrated into the final version. Then, the final updated version of the platform resources was communicated to the work team of each university.

\section{Case Study: The Virtual Practical Activity of the Prism}

Physics is a scientific practical discipline. It is a subject where actual doing is the key for permitting learners to apply their knowledge and develop their skills. Furthermore, geometrical optics is a model of optics that describes light propagation in terms of rays. This case study presents the virtual practical activity of the prism developed by the Cadi Ayyad University team.

\subsection{Optical Prism}

An optical prism is solid, transparent glass, an optical system formed by two nonparallel flat surfaces, creating an angle between them, and it is characterized by its refractive index $\mathrm{n}$. The prism is used to refract and reflect light, or to decompose and split white light into its different colors, or to measure a refractive index. The traditional geometrical shape of an optical prism is a triangular prism with a triangular base and rectangular sides (Figure 7).

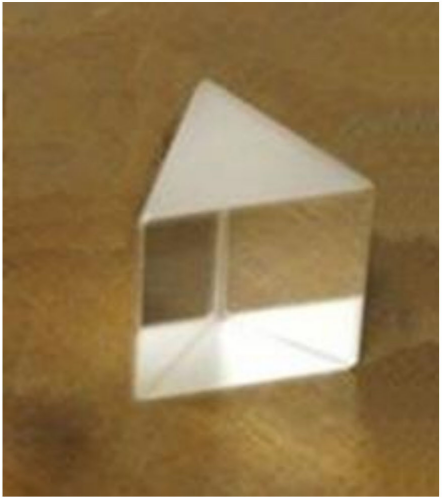

(a)

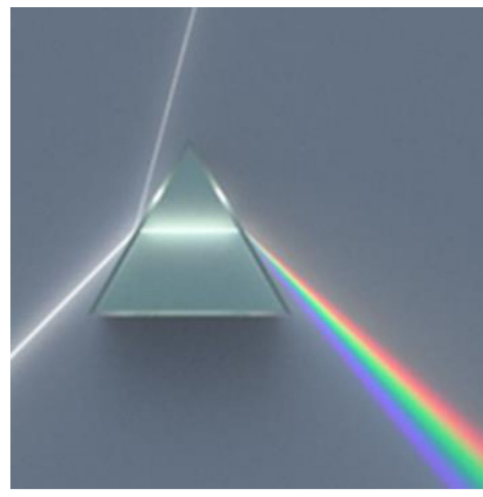

(b)

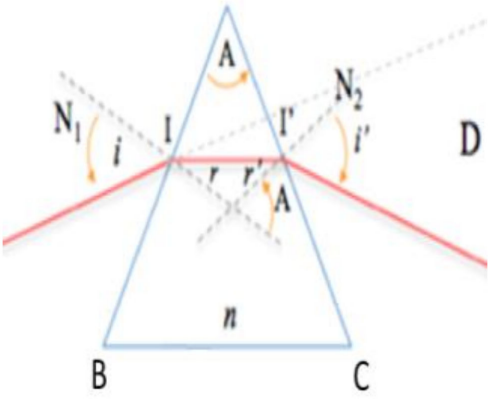

(c)

Figure 7. Optical prism: (a) the traditional geometrical shape of an optical prism; (b) the propagation and dispersion of a white light ray by a prism; (c) light propagation by the prism and its formed angles.

\subsection{The Virtual Practical Activity of the Prism}

In geometrical optics, the light propagates in a straight line in a transparent, homogeneous, and isotropic medium. When a light ray passes from one medium to another it undergoes refractions and/or reflections. The virtual practical activity of the prism aims to study the propagation of a light ray: the refraction, reflection, deviation, and dispersion of white light by the prism. The skills targeted through these simulated activities enable learners to understand and analyze the propagation of light by a prism. To do this, three investigations were created:

1. Investigation 1: study of the path of a light ray by a prism and the determination of prism equations.

2. Investigation 2: study of the deviation by a prism and the determination of the minimum angle of deviation (Dm).

3. Investigation 3: study of the dispersion of light by a prism. 
In the developed graphical interfaces of the simulations, the learner can use a light ray (laser) and a prism and can modify the position and color of the laser as required by questions of the experimental protocol. The learner can also display and use the protractor to measure the values of angles, and use the other simulation tools provided as explained and according to his or her needs.

The first investigation aimed to highlight the propagation of a light ray by a prism (Figure 8). The learner is required to verify by an experimental method the laws of refraction and reflection for a prism, and to study the case of total reflection, as well as to verify the conditions of emergence of the light ray from the prism, and then determine the prism equations shown below and detailed in Figure 7c.

$$
\begin{gathered}
\sin i=n \sin r, \\
n \sin r^{\prime}=\sin i^{\prime}, \\
A=r+r^{\prime}, \\
D=i+i^{\prime}-A .
\end{gathered}
$$

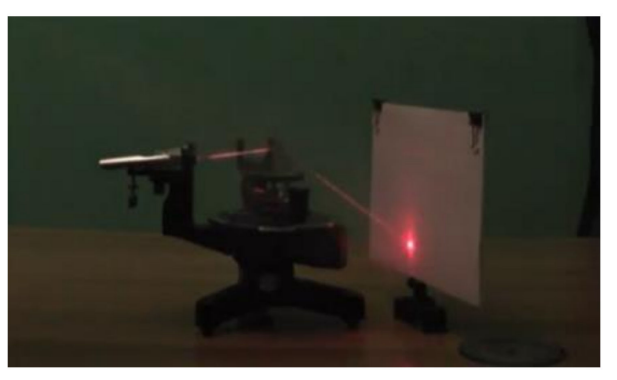

(a)

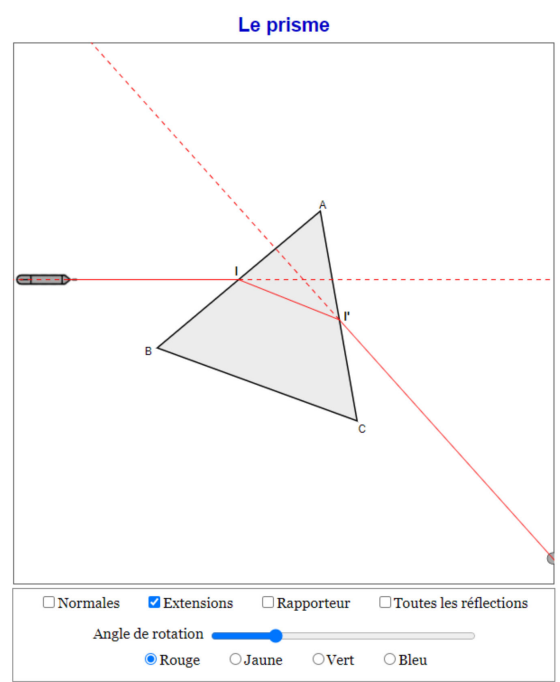

(b)

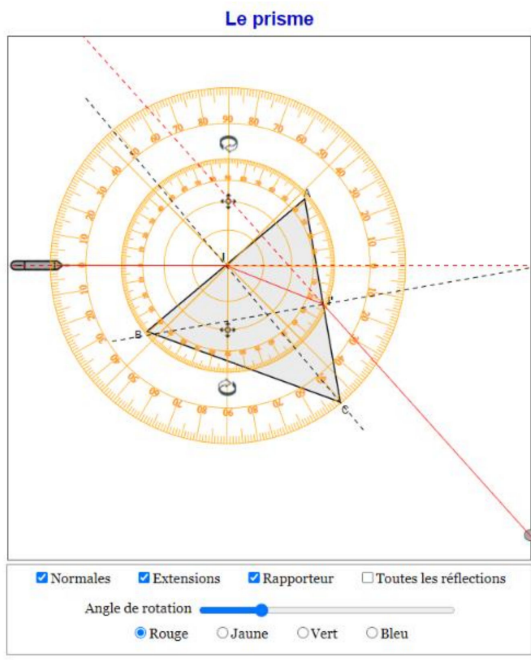

(c)

Figure 8. Experiment 1: study of the path of a light ray by the prism: $(\mathbf{a})$ image from the laboratory video; $(\mathbf{b}, \mathbf{c})$ images from the simulation.

The second investigation aimed to study the deviation variations depending on the angle of incidence and to determine the angle of the minimum deviation (Figure 9), and then to calculate the index of the prism used in the experiment.

The third investigation aimed to present the phenomenon of the dispersion of white light (Figure 10); it allows the learner to observe and describe the spectrum of light obtained. 

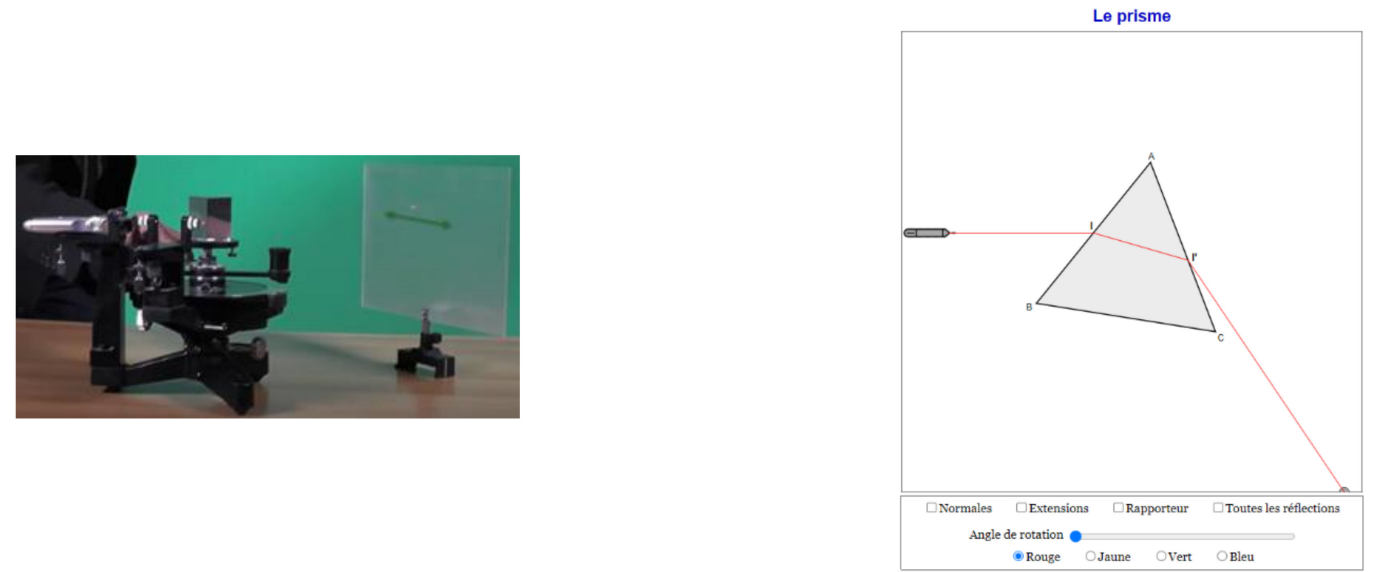

(a)
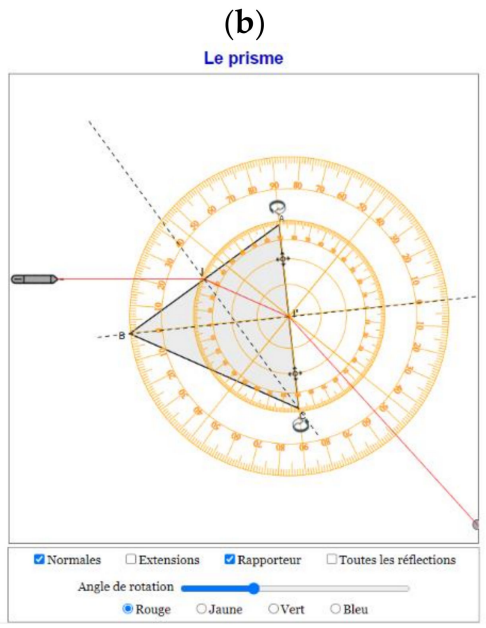

(c)

(d)

Figure 9. Experiment 2: study of the minimum of deviation: $(\mathbf{a}, \mathbf{c})$ images from the laboratory video; $(\mathbf{b}, \mathbf{d})$ images from the simulation.

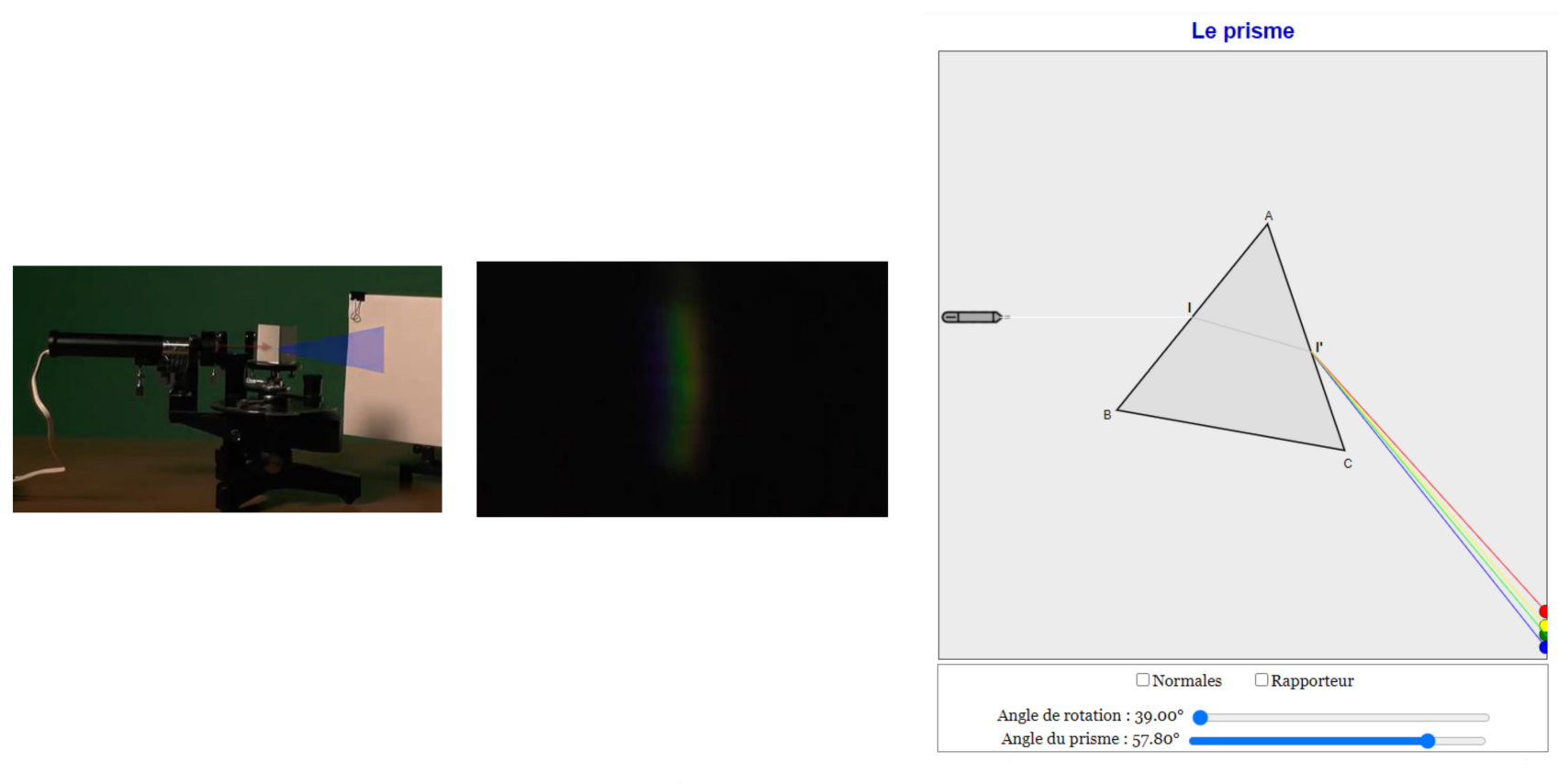

(a)

(b)

(c)

Figure 10. Experiment 3: study of the dispersion of the white light by a prism: (a,b) images from the laboratory video; (c) image from the simulation. 


\subsection{The Sequence of Carrying Out a Virtual Practical Activity}

After authentication to the platform, the learner chooses the practical activity to be carried out from the 12 proposed practical activities. Once the activity is accessed, a list of different resources is offered (Table 2); the learner should view these resources and run them in chronological order.

Table 2. The different resources of a virtual practical activity.

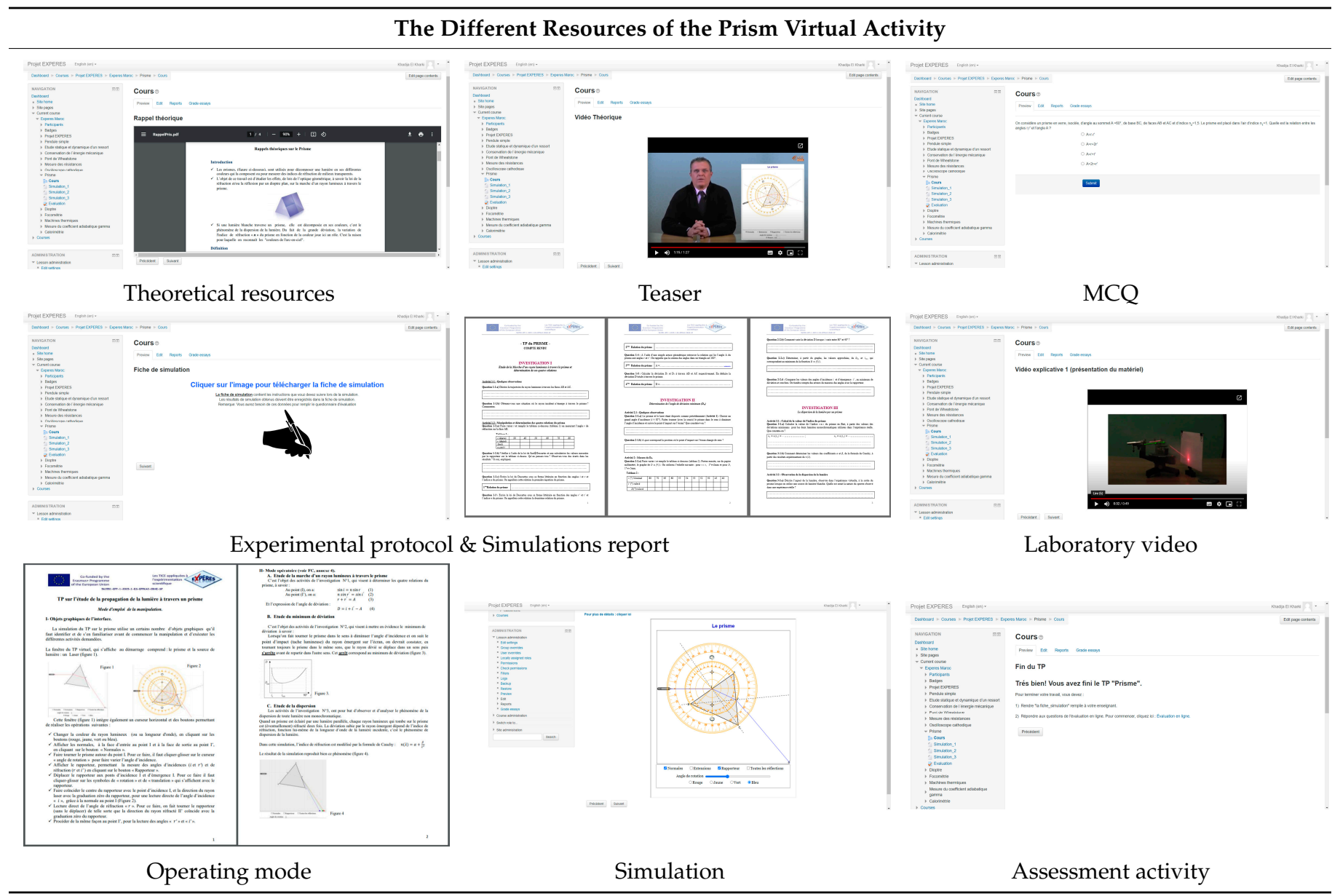

First, the learner consults the theoretical course reminder, then contributes to a MCQ formative assessment. Next, the learner watches the teaser and the laboratory video of each activity, then displays the simulation report and the operating mode. After that, the learner manipulates the simulation according to the experimental protocol and answers the questions of the simulation report. Finally, the learner does the assessment activity and submits it to the tutor.

The platform offers the learner flexibility to work. For example, if he/she is unable to complete the activity which he/she has started, when he/she next connects to the same activity, the platform offers him/her the possibility to finish the activity from the stage where he/she has stopped or to restart the activity.

The learner can also consult or ask questions in the discussion forum. In cases of difficulties related to using the platform, the learner can consult the guide that explains the use of the platform in detail.

\subsection{The Learner Activities Tracking}

The Moodle platform offered many ways and reports for monitoring the learner's activities (Figure 11). For the developed platform, the learner activities tracking was ensured through the simulation report and the assignment activity. The learner manipulates 
the simulations according to the experimental protocol, the obtained measurements are noted in the simulation report. At the end of the activity, the learner copies his/her answers from the simulation report to the assignment activity and sends them on the platform. For some short answers, the learner receives feedback immediately and for other answers, he/she waits until the teacher or tutor correction.

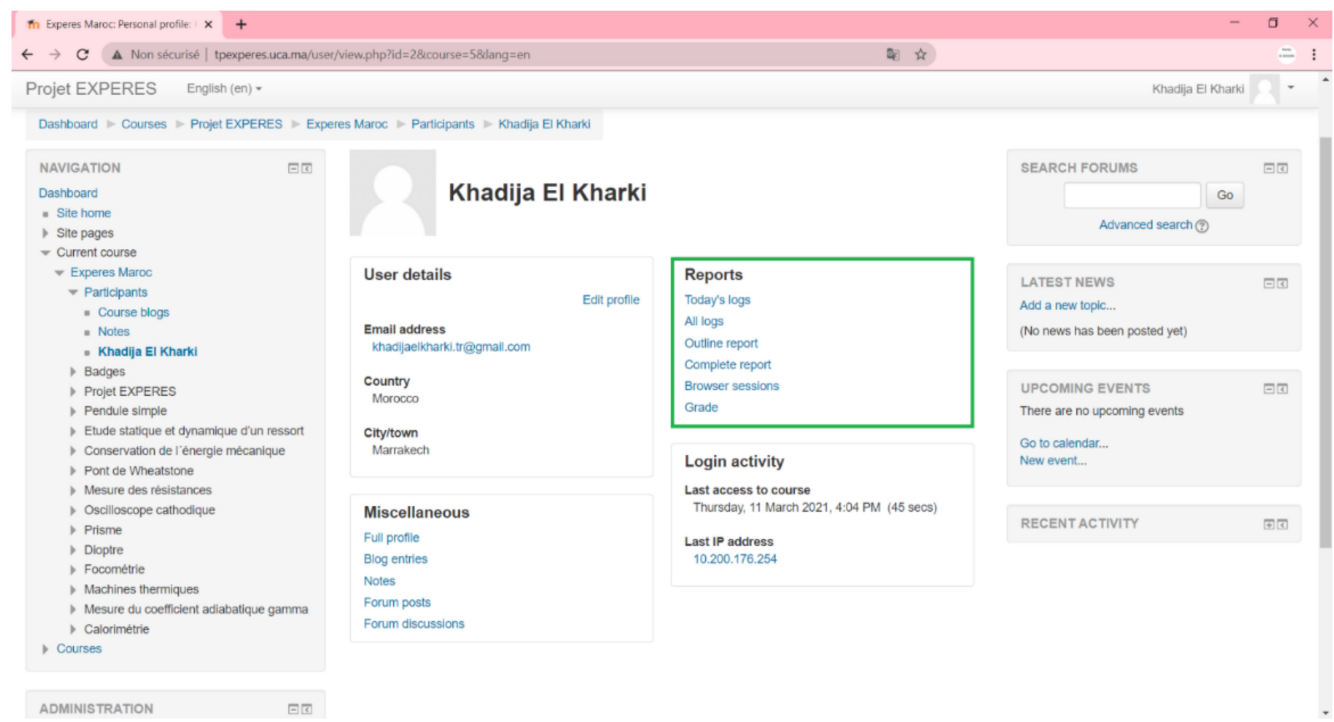

Figure 11. Monitoring of learner activities on the Moodle platform.

\section{Results and Discussion}

\subsection{The Developed Virtual Laboratory}

It is difficult to obtain an understanding of scientific theories without scientific laboratory activities. In order to provide an alternative to actual physics laboratory activities for learners in the first year of their bachelor's degree, an interactive virtual laboratory integrated into an appropriate online learning environment was implemented in the Moroccan science faculties. The virtual laboratory offered the opportunity to carry out the practical laboratory work virtually by providing computer simulations that give designs and ways of work that are similar to actual experiments.

Twelve virtual practical activities that are mapped to the physics curriculum of the first year of the bachelor's degree were created, developed, implemented, and are accessible via the dedicated educational platform (http: / / www.tpexperes.uca.ma/, accessed on 26 October 2020). These are mainly the same practical work provided in semesters S1 and S2 in higher education institutions in Morocco. Tables 3-6 present a summary of all practical activities produced, which covered the four disciplinary fields of physics (mechanics, thermodynamics, electricity, and optics) that are taught in the first year.

Traditional laboratories provide physical infrastructure but may have location limitations and scheduling and financial issues [90]. Virtual laboratories are becoming mainstream in higher education for science and engineering in many countries around the world [8]. Furthermore, they are very effective learning environments, with great potential for performance at a low cost [91]. Also, technological advancements in education have made it possible for everyone to participate in the virtual world [92] and enjoy the major benefits of the easy transfer of information and connectivity. These characteristics are making it possible for learners to choose when, how, and where to learn [93]. Also, the use of ICT has the potential to enhance the quality of teaching and learning [94]. 
Table 3. Presentation of virtual practical work produced for the mechanics module.

\begin{tabular}{|c|c|c|}
\hline $\begin{array}{l}\text { Simulations Developed for } \\
\text { the Mechanics Module }\end{array}$ & Manipulation Title & Objective of the Virtual Practical Activity \\
\hline - & Simple pendulum & $\begin{array}{l}\text { Determine the period of a simple pendulum and study } \\
\text { the influences of the mass and length of the wire on this } \\
\text { period and prove the theoretical relationship between } \\
\text { the period and the length of the wire. Finally, deduce the } \\
\text { acceleration of gravity and the mass of the earth. }\end{array}$ \\
\hline 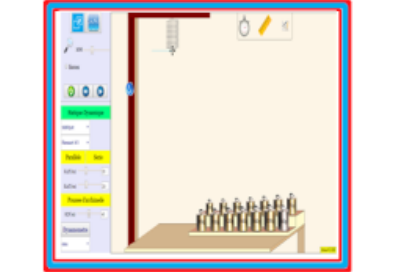 & Static and dynamic study of springs & $\begin{array}{l}\text { Discover and demonstrate the movement of an elastic } \\
\text { pendulum, identify and measure the amplitude and } \\
\text { period of the oscillations, and determine the spring } \\
\text { stiffness constant by two methods: static and dynamic. } \\
\text { Also, study a mechanical system composed of two } \\
\text { springs in parallel or series and verify the Archimedes } \\
\text { thrust on an object immersed in a liquid. }\end{array}$ \\
\hline $\begin{array}{c}0 \\
-1000 \\
-10\end{array}$ & Conservation of mechanical energy & $\begin{array}{l}\text { Study the evolution of kinetic, potential, and mechanical } \\
\text { energies over time. Also, understand the principle of } \\
\text { total energy conservation through studying the } \\
\text { conservation or not of mechanical energy: (a) for the free } \\
\text { fall of an object and the fall into a fluid, and (b) for an } \\
\text { oscillating system with or without dissipation. }\end{array}$ \\
\hline
\end{tabular}

Table 4. Presentation of virtual practical work produced for the thermodynamics module.

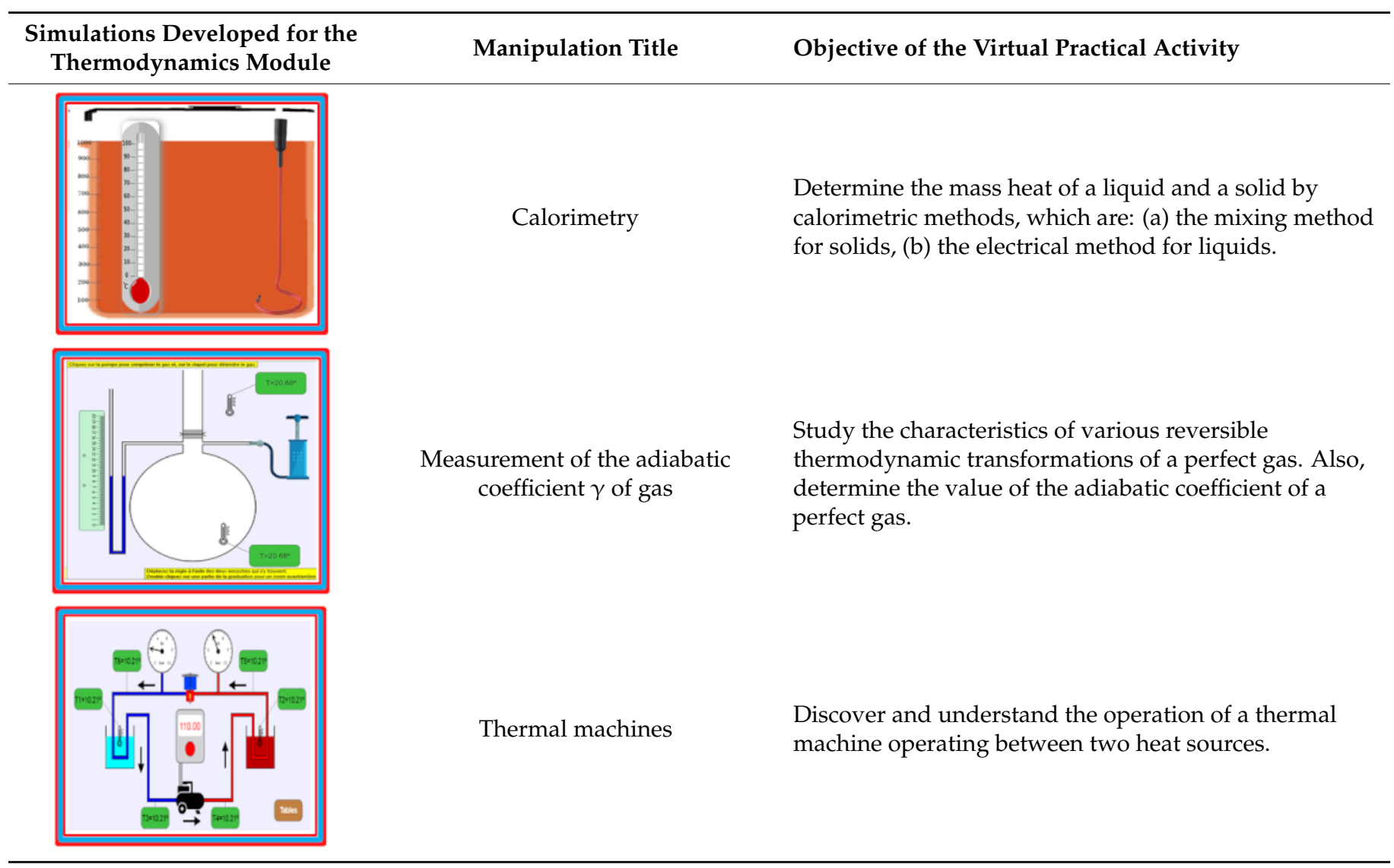


Table 5. Presentation of virtual practical work produced for the electricity module.

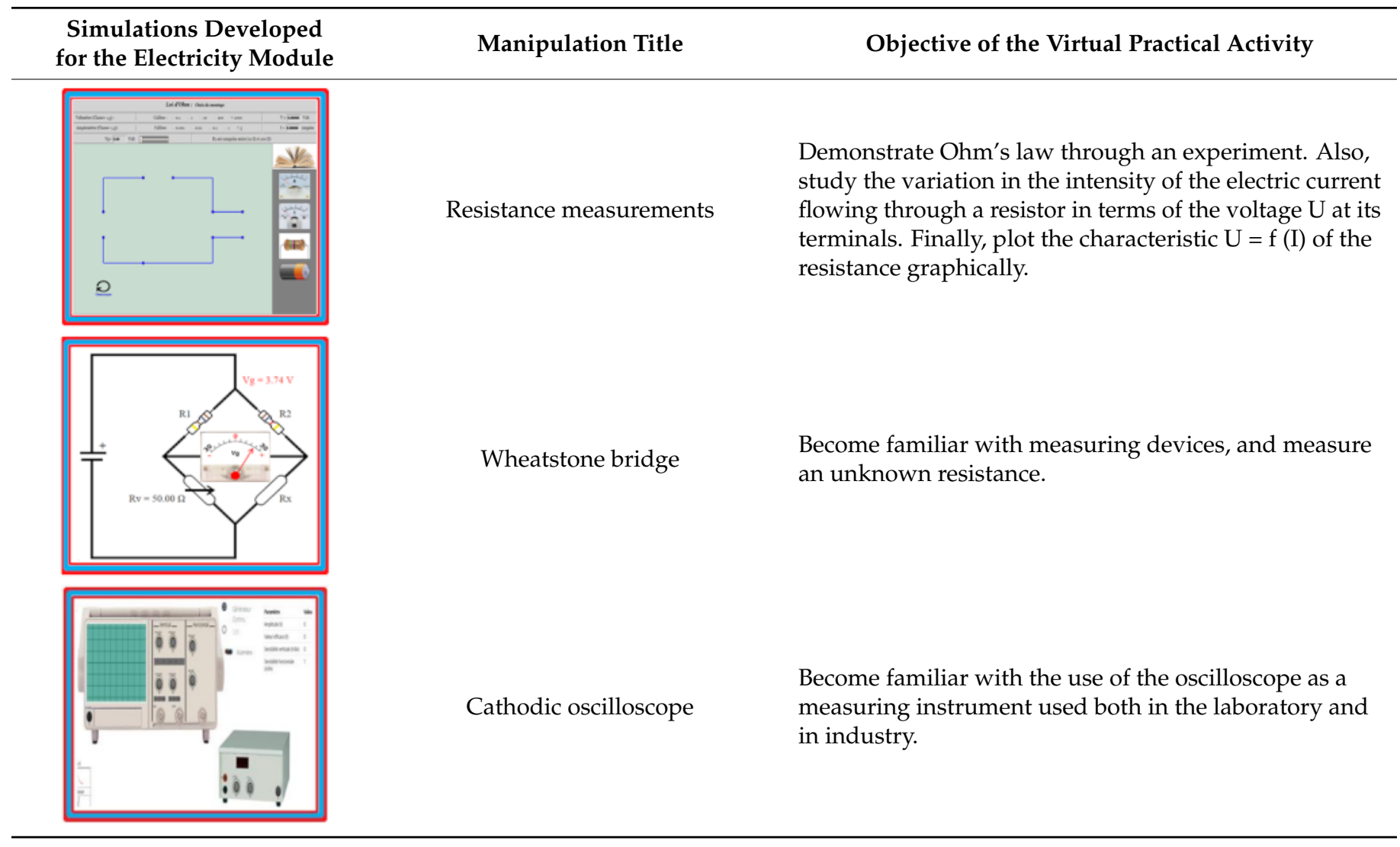

Table 6. Presentation of virtual practical work produced for the optics module.

\begin{tabular}{|c|c|c|}
\hline $\begin{array}{l}\text { Simulations Developed } \\
\text { for the Optics Module }\end{array}$ & Manipulation Title & Objective of the Virtual Practical Activity \\
\hline & Diopter & $\begin{array}{l}\text { Study the refraction and reflection of light as it passes between } \\
\text { two media with different indices. Find the laws of reflection and } \\
\text { refraction. Also, study the refraction from a less refractive } \\
\text { medium to a more refractive medium and vice versa. Finally, } \\
\text { highlight the phenomenon of total reflection. }\end{array}$ \\
\hline & Prism & $\begin{array}{l}\text { Study the propagation of a light ray: the refraction, reflection, } \\
\text { deviation, and dispersion of white light by the prism and the } \\
\text { determination of the prism equations. }\end{array}$ \\
\hline & Focometry & $\begin{array}{l}\text { Visualize the position and size of the image according to the } \\
\text { position of the object and verify the magnification relationship. } \\
\text { Also, verify the conjugate relation of a lens. Finally, determine, by } \\
\text { different methods, the focal length of a thin converging lens and a } \\
\text { diverging lens. }\end{array}$ \\
\hline
\end{tabular}


In addition, the virtual learning environment not only provides rich teaching models and learning content, but also helps improve the ability of learners to analyze problems and explore new concepts [95]. Presently, there are numerous examples of virtual laboratories applied to different scientific subjects, such as physics. Redel-Macías et al.'s [91] study results showed that learners prefer conducting experiments in virtual laboratories instead of physical ones since the former are easier to understand and perform than the latter, with the help of appropriate software applications.

Furthermore, the virtual practical learning environment substitutes for physical laboratory practices by providing similar experiments. Consequently, learners are able to undertake laboratory experiments without having to be in a physical laboratory [14].

The use of the virtual laboratory based on computer simulation and the Moodle platform as a collaborative environment for doing practical activities has many advantages for learners, such as preventing feelings of isolation, increasing flexibility, and effectively augmenting their motivation and productivity by providing feedback on their results and allowing discussion of questions through synchronous and asynchronous discussion forums. Further, the virtual laboratory enhances and improves the quality of learning because learners have unlimited access and can easily repeat the experiments as many times as necessary, at any time and from any place using their computers and an Internet connection $[79,96]$. Likewise, there is vast evidence that learning outcomes from using a virtual laboratory are at least equal to outcomes from traditional laboratories $[59,62,65,97,98]$. In addition, virtual laboratories have several advantages over traditional laboratories: they are cheaper as no materials or equipment are required, they have less environmental impact (no waste), and there is no need for preparation beforehand and cleaning [99]. As well, virtual laboratories need less maintenance than traditional ones, which makes them more sustainable, and therefore the virtual laboratories are certainly a means to support the sustainability of universities [57].

\subsection{Learner Satisfaction}

After the implementation of the virtual laboratory of physics at the Cadi Ayyad University in Marrakech, we used a survey instrument for gathering information regarding the practical content delivery in the newly developed learning environment. The survey was conducted anonymously with the use of Google Forms. The survey contained questions intended to collect the learners' opinions and level of satisfaction concerning the platform and the virtual laboratory activities produced. The percentage of responses was about $40 \%$. The following table (Table 7) illustrates the opinions obtained from 120 learners from the science faculty, engineering schools, science and technology faculty, and poly-disciplinary faculty of the Cadi Ayyad University.

In general, the table shows that the new proposed learning environment for virtual practical activities was evaluated positively by learners. For all questions, an average of over 59\% responded "Yes! Perfectly," and over 27\% responded "Medium." Also, about $6 \%$ answered by "No! not at all"; this can be justified by the reason that just three virtual practical activities for each physics module were not enough and did not cover all the content of the course. As well, about 6\% mentioned "I don't know" because they thought that they did not need practical activities in the first year, since the virtual activities were not officially approved in the curriculum by the Ministry of Higher Education.

Figure 12 displays the learners' global level of satisfaction regarding the platform; $53.33 \%$ said that the platform set-up was very satisfactory, and $35.83 \%$ said satisfactory.

The learners' feedback indicated that they liked the new practical working environment and felt encouraged to learn more effectively in this way [100], in addition, they demanded to add other virtual activities to the platform, for covering all chapters of the physics course. Also, it was proven that the use of virtual laboratories can positively impact learners' knowledge, skills, and attitudes. 
Table 7. Learners' opinions about the platform and the virtual laboratory activities produced.

\begin{tabular}{|c|c|c|c|c|}
\hline & I Don't Know & No! Not at All & Medium & Yes! Perfectly \\
\hline Was the novelty of the work environment motivating for you? & $1.67 \%$ & $4.17 \%$ & $17.50 \%$ & $76.67 \%$ \\
\hline Was it easy to access the platform? & $3.33 \%$ & $2.50 \%$ & $36.67 \%$ & $57.50 \%$ \\
\hline Was it easy to register on the platform? & $2.50 \%$ & $5 \%$ & $16.67 \%$ & $75.83 \%$ \\
\hline Was it easy to navigate in the platform? & $4.17 \%$ & $8.33 \%$ & $26.67 \%$ & $60.83 \%$ \\
\hline $\begin{array}{l}\text { Were all of the platform's activities functional and } \\
\text { easily accessible? }\end{array}$ & $6.67 \%$ & $5 \%$ & $13.33 \%$ & $75 \%$ \\
\hline Did the pre-test support the learning of theoretical knowledge? & $3.33 \%$ & $11.67 \%$ & $30 \%$ & $55 \%$ \\
\hline $\begin{array}{l}\text { Was the proposed activity on the knowledge test clearly } \\
\text { organized and achievable? }\end{array}$ & $6.67 \%$ & $5.83 \%$ & $41.67 \%$ & $45.83 \%$ \\
\hline $\begin{array}{l}\text { Was the proposed activity proposed on the simulation report } \\
\text { clearly organized? }\end{array}$ & $7.50 \%$ & $5 \%$ & $20.83 \%$ & $66.67 \%$ \\
\hline $\begin{array}{l}\text { Was the proposed activity on the assessment test } \\
\text { clearly organized? }\end{array}$ & $5.83 \%$ & $8.33 \%$ & $26.67 \%$ & $59.17 \%$ \\
\hline $\begin{array}{l}\text { Were the simulation instructions for the practical activities clear } \\
\text { and sufficient? }\end{array}$ & $7.50 \%$ & $3.33 \%$ & $24.17 \%$ & $65 \%$ \\
\hline $\begin{array}{l}\text { Was the simulation understandable, making it possible to } \\
\text { approach the experimental conditions and assimilate the } \\
\text { theoretical aspects? }\end{array}$ & $9.17 \%$ & $3.33 \%$ & $30 \%$ & $57.50 \%$ \\
\hline Did the assessment focus on the skills/knowledge taught? & $7.50 \%$ & $5.83 \%$ & $24.17 \%$ & $62.50 \%$ \\
\hline Was the average duration of a practical work suitable? & $8.33 \%$ & $2.50 \%$ & $42.50 \%$ & $46.67 \%$ \\
\hline Did the platform meet your expectations? & $5.83 \%$ & $10 \%$ & $41.67 \%$ & $42.50 \%$ \\
\hline Have these virtual practical activities been beneficial to you? & $6.67 \%$ & $5 \%$ & $20.00 \%$ & $68.33 \%$ \\
\hline
\end{tabular}

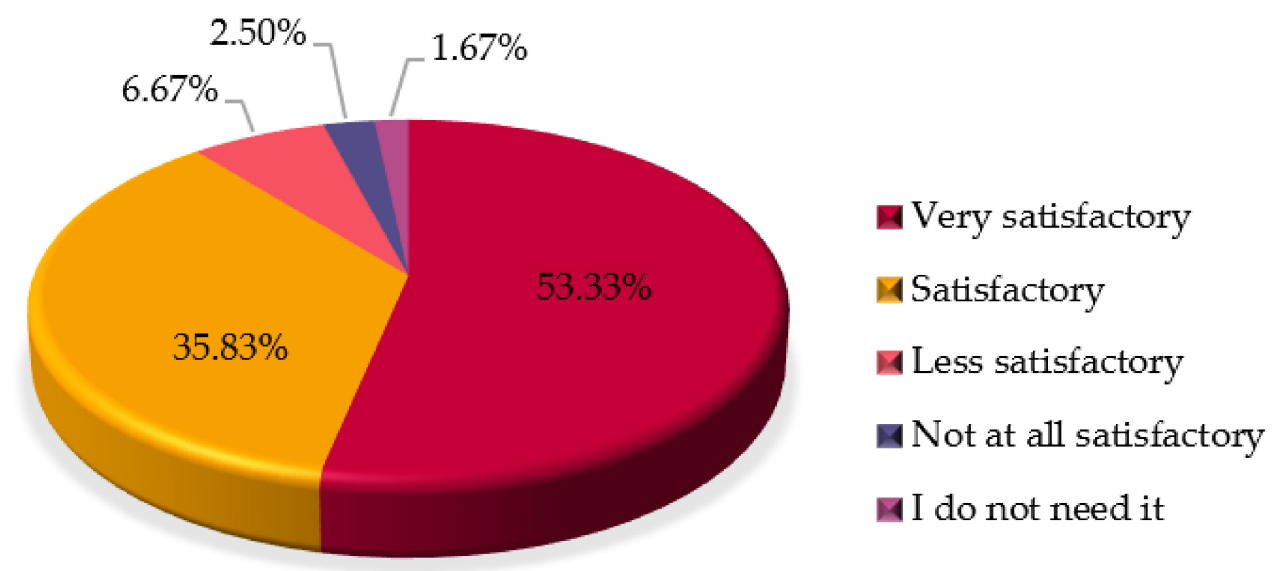

Figure 12. Learners' global level of satisfaction regarding the platform of the physics virtual practical work.

\subsection{Teachers' Opinions}

Before starting the development of the virtual practical environment, teachers of physics from all Moroccan science faculties were asked through a survey to give their opinions about the efficiency of setting up a virtual laboratory as an alternative solution to the eliminated practical work of the physical hands-on laboratory of physics. Figures 13-16 present the statements obtained from the teachers from nine universities.

For all the survey questions, a good percentage (over $80 \%$ ) of teachers supported the creation of a virtual environment as a solution to maintain the laboratory activities and their contributions to the improvement of learning. 


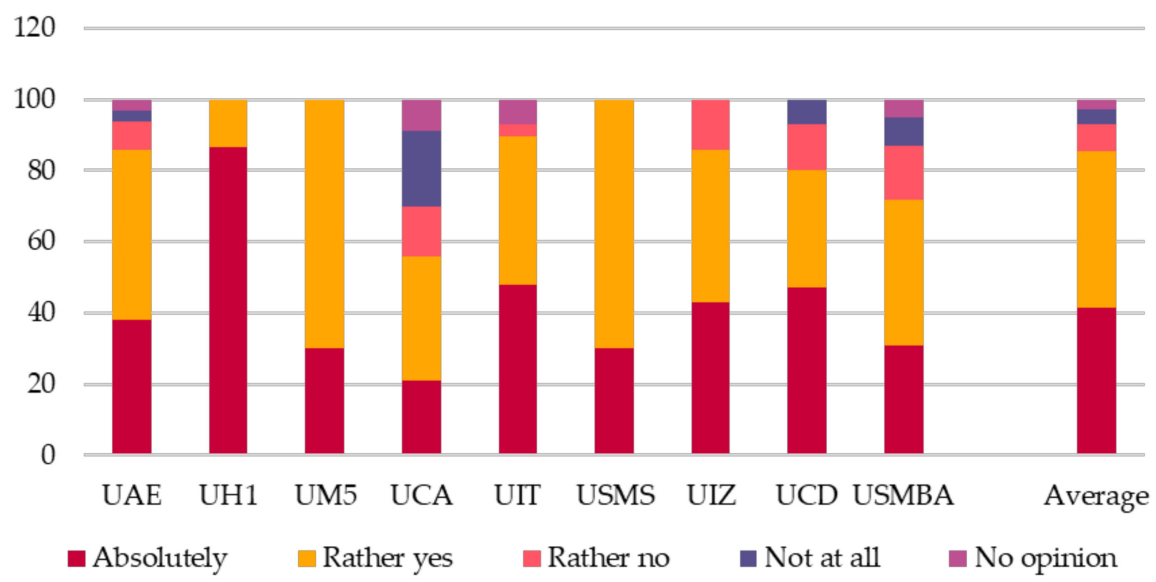

Figure 13. Teachers' opinions on using virtual learning to improve or maintain the practical teaching provided in the first year for the physics subject.

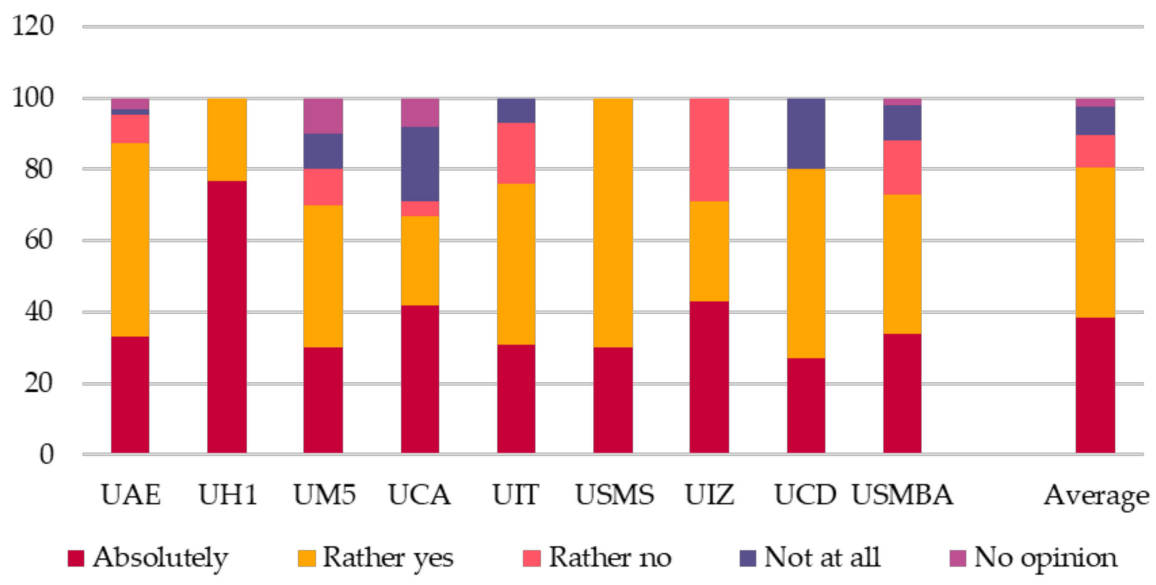

Figure 14. Teachers' opinions on the contribution of virtual practical activities to improve learning.

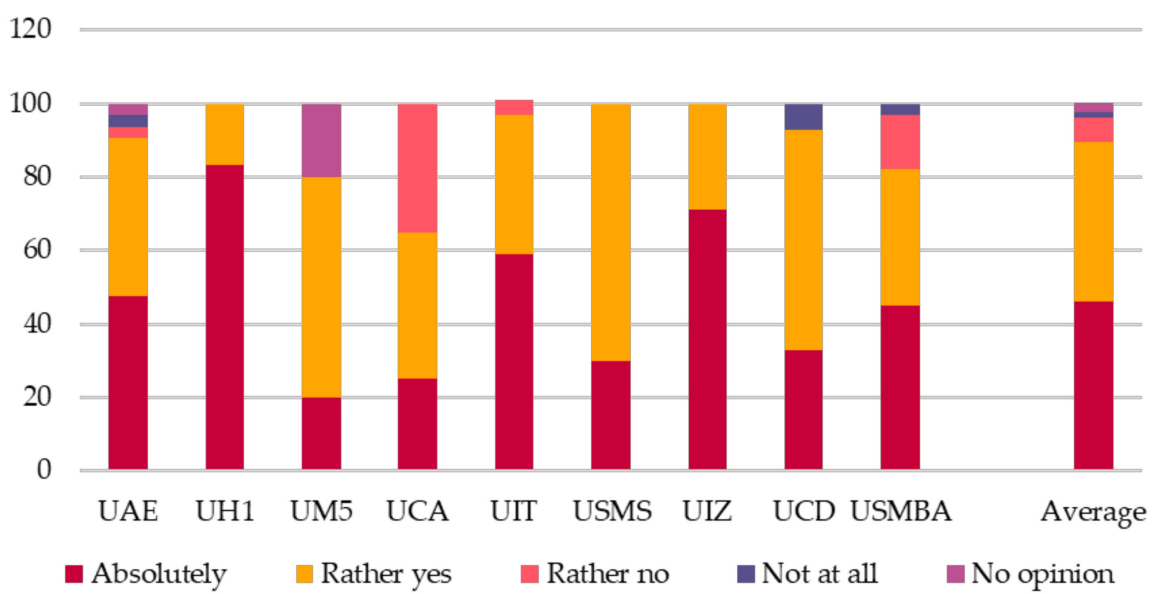

Figure 15. Teachers' opinions on the use of virtual practical activities to support practical teaching. 


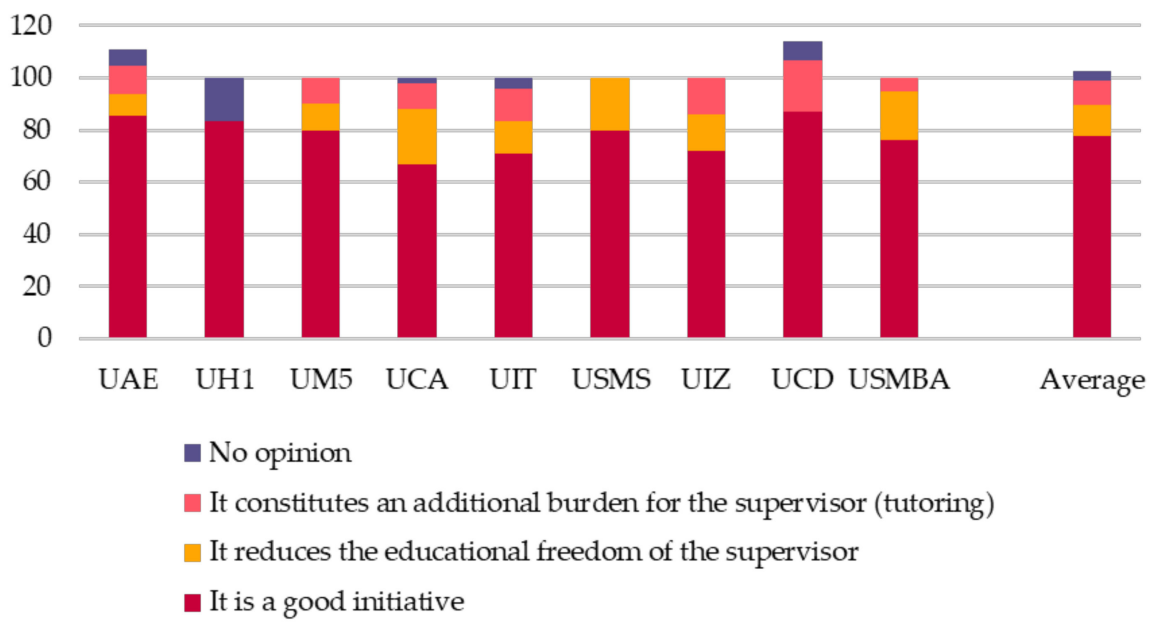

Figure 16. Teachers' opinions on the initiative proposed by the EXPERES project.

However, resistance to virtual laboratories is still prevalent [65] because some science teachers discouraged replacing traditional hands-on, face-to-face laboratories with virtual laboratories [59]. They argued that traditional face-to-face laboratories are often seen as an opportunity for learners to practice inquiry skills and scientific process skills, which may be another reason for choosing a hands-on format. Besides, not all laboratory practices can be simulated and reproduced on a computer, nor can all the practical skills be acquired through virtual experimentation [57]. Nevertheless, virtual laboratories are being used to respond to the need of improving learning and expanding educational opportunities for more scientific learners.

After the implementation of the developed virtual learning environment, we recently conducted a new survey for the second year of the implementation of the project, in order to collect the opinions and verify the satisfaction of teachers from the science faculty at Cadi Ayyad University. Teachers who participated in the elaboration of the virtual practical activities, in addition to teachers who experienced these activities, were asked through this survey to give their opinion and express their satisfaction about the platform. A total of $93 \%$ of the investigated teachers declared that they utilized the platform for the practical teaching, for the four physics modules (mechanics, thermodynamics, electricity, and optics). Also, teachers were invited to express their opinions about the platform and the virtual laboratory activities produced. Table 8 illustrates the obtained results from 30 teachers who responded to the survey.

Table 8. Teachers' opinions about the platform and the virtual laboratory activities produced.

\begin{tabular}{|c|c|c|c|c|}
\hline & Not at All & Rather No & Rather Yes & Absolutely \\
\hline Was the novelty of the work environment motivating for the learners? & $0 \%$ & $0 \%$ & $40 \%$ & $60 \%$ \\
\hline Was the virtual learning environment well structured? & $0 \%$ & $0 \%$ & $40 \%$ & $60 \%$ \\
\hline Are all of the platform's activities functional and easily accessible? & $0 \%$ & $0 \%$ & $47 \%$ & $53 \%$ \\
\hline Were the virtual activities well structured? & $0 \%$ & $3 \%$ & $37 \%$ & $60 \%$ \\
\hline $\begin{array}{l}\text { Did the content of the virtual hands-on activities support the learning of } \\
\text { theoretical knowledge? }\end{array}$ & $0 \%$ & $3 \%$ & $17 \%$ & $80 \%$ \\
\hline $\begin{array}{l}\text { Was the simulation understandable, allowing you to approach the } \\
\text { experimental conditions and assimilate the theoretical aspects? }\end{array}$ & $0 \%$ & $3 \%$ & $27 \%$ & $70 \%$ \\
\hline Were the additional resources very helpful? & $0 \%$ & $0 \%$ & $23 \%$ & $77 \%$ \\
\hline Was it easy to navigate the platform? & $0 \%$ & $0 \%$ & $40 \%$ & $60 \%$ \\
\hline Did the platform meet your expectations? & $0 \%$ & $0 \%$ & $37 \%$ & $63 \%$ \\
\hline $\begin{array}{l}\text { In the absence of the first year physics laboratory activities, were these } \\
\text { virtual activities useful for learners? }\end{array}$ & $0 \%$ & $0 \%$ & $20 \%$ & $80 \%$ \\
\hline
\end{tabular}


The online virtual learning environment was also evaluated very positively by teachers; for all questions, over $99 \%$ of teachers gave good and positive opinions about the effectiveness and usefulness of the online simulations and the platform resources. For all questions, an average of over 66\% responded "Yes! Perfectly" and over 32\% responded "Medium".

Figure 17 displays the teachers' global level of satisfaction regarding the platform; $65 \%$ said that the platform set-up was very satisfactory, and $35 \%$ said that was satisfactory.

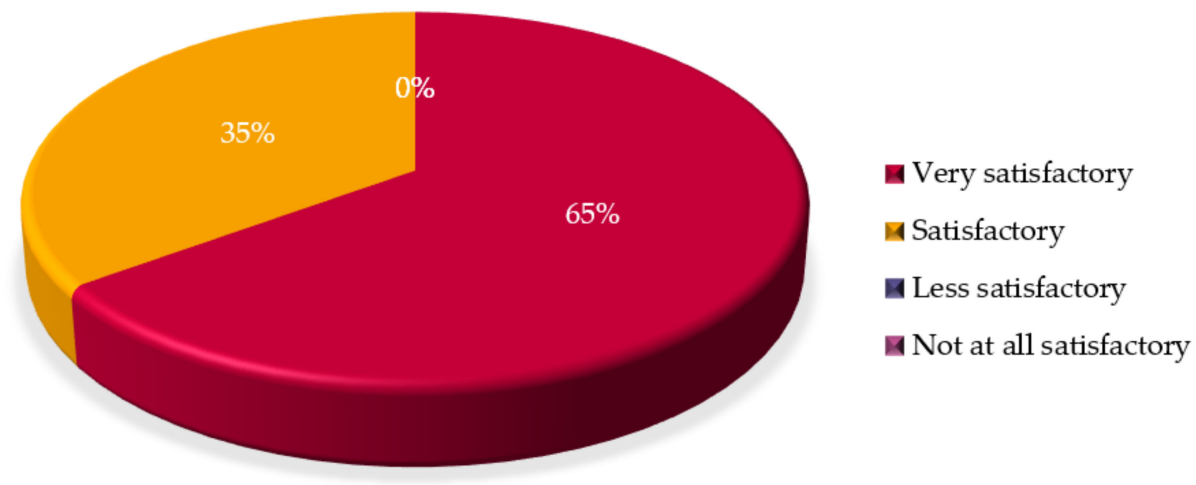

Figure 17. Teachers' global level of satisfaction regarding the platform of the physics virtual practical work.

In another question, teachers were invited to give their recommendations for the promotion of the practical online learning environment. The main directions given were:

- Developing and adding other virtual activities to cover the entire physics course;

- Adapting and adjusting the simulations for the smartphone's screen;

- Updating the platform to the new version of Moodle;

- Improving the platform ergonomics;

- $\quad$ Diversifying disciplines;

- Generalizing and formalizing the experience in an institutional way.

Indeed, future efforts will continue the improvement of the virtual laboratory according to the given recommendations.

Another interesting point is that the virtual laboratory could be used as supplemental or pre-laboratory exercises by higher education institutions in Morocco with limited access, for training learners who perform hands-on activities in physical laboratories. In this case, learners achieve some of the reasoning skills and knowledge that they may further combine with practical experimental designs and performance in the physical laboratory sessions. However, virtual laboratories and simulations, when used as pre-laboratory exercises, can positively impact learning and performance [88,92]. Studies from [101-103] have shown that combinations of virtual and hands-on laboratory environments result in better content knowledge compared to using one type of environment alone.

\section{Conclusions}

Laboratory learning is a requirement for science education, especially as it offers learners the possibility to get practical experience. This paper presented an interactive proposed solution to surmount the lack of practical physics activities in the science faculties in Morocco. A virtual laboratory that can be operated via the web and uses computer simulation to illustrate actual physics experiments was developed to support the teaching of physics in science learners' first year.

The ADDIE (Analysis, Design, Development, Implementation, and Evaluation) model for the online teaching content design was adopted as the main methodology for the development process. This paper also presented the tools employed for the development of the virtual laboratory environment: EJSS software was used to create the simulations 
that support the JavaScript codes, and the Moodle platform was used to host and deploy the virtual simulations, with additional appropriate resources created for offering learners a collaborative learning environment.

Twelve virtual experiments were developed as part of the EXPERES project, with the participation of the 12 universities. They cover the four disciplinary fields of physics (mechanics, thermodynamics, electricity, and optics) that are taught in the first year. The virtual activities were tested by learners taking physics courses in science faculties. Learners could conduct experiments in the faculties' computer centers or at home, and the virtual laboratory increased flexibility and learner motivation and provided similar learning achievements to a physical laboratory.

In summary, the effectiveness and usefulness of the virtual laboratory was evaluated positively by teachers and learners; also, learners appreciated the virtual laboratory experience because it increased their motivation to learn physics. In addition, the feedback collected from the learners and teachers indicated that the developed virtual laboratory supported the learners' understanding of the scientific concept of physics.

There is no doubt that not all the practices of a real laboratory can be reproduced by simulation in the virtual laboratory, but at the same time, the effectiveness of the use of virtual laboratories for science education has been proven by several studies. Furthermore, they are great tools for ensuring as well as promoting the sustainability of scientific teaching in higher education.

Finally, the tools presented in this paper are a generic framework that can be applied to many scientific and technical courses that need to provide virtual experimentation as a complement to the theoretical courses. As another perspective of this work, we are working on the development of a virtual laboratory for chemical practical activities by utilizing the same methodologies and tools.

Author Contributions: For this article, contributions have been done in agreement between authors as follows. Conceptualization, K.E.K. and K.B.; methodology, K.B.; software, K.E.K.; validation, K.E.K., K.B. and D.B.; formal analysis, K.E.K.; investigation, K.E.K.; resources, K.E.K., K.B.; data curation, K.E.K.; writing—original draft preparation, K.E.K.; writing—review and editing, K.E.K., K.B. and D.B.; visualization, K.E.K.; supervision, K.B. and D.B. All authors have read and agreed to the published version of the manuscript.

Funding: This research received no external funding.

Institutional Review Board Statement: Not applicable.

Informed Consent Statement: Informed consent was obtained from all subjects involved in the study.

Data Availability Statement: The data presented in this study are available on request from the corresponding author.

Acknowledgments: The authors would like to thank all our partners for their involvement in the EXPERES project. Our thanks also to the European Commission for funding and supporting EXPERES in Moroccan universities. Special thanks to the University of Murcia and the University of Abdelmalek Essaadi for offering us the opportunity to work in consortium and for their coordination of EXPERES. Thanks also to all UCA team members for believing in this idea from the beginning and for their engagement, which was the success of the project.

Conflicts of Interest: The authors declare no conflict of interest.

\section{References}

1. De Jong, T.; Linn, M.C.; Zacharia, Z.C. Physical and virtual laboratories in science and engineering education. Science (80-) 2013, 340, 305-308. [CrossRef] [PubMed]

2. Thomas, I. Pedagogy for Education for Sustainability in Higher Education. Sustainability 2014, 6, 1705-1708. [CrossRef]

3. Ünal, F.; Kaygin, H. Citizenship education for adults for sustainable democratic societies. Sustainability 2020, 12, 56. [CrossRef]

4. Bybee, R.W. The Case for STEM Education: Challenges and Opportunities; NSTA Press: Arlington, VA, USA, 2013.

5. Clark, J.; White, G.W. Experiential learning: A definitive edge in the job market. Am. J. Bus. Educ. 2010, 3, 115-118. [CrossRef] 
6. Feisel, L.D.; Rosa, A.J. The role of the laboratory in undergraduate engineering education. J. Eng. Educ. 2005, 94, 121-130. [CrossRef]

7. Singer, S.R.; Hilton, M.L.; Schweingruber, H.A. America's Lab Report: Investigations in High School Science. Committee on High School Science Laboratories: Role and Vision; National Academic Press: Washington, DC, USA, 2006.

8. Chen, S. The view of scientific inquiry conveyed by simulation-based virtual laboratories. Comput. Educ. 2010, 55, 1123-1130. [CrossRef]

9. Satterthwait, D. Why are 'hands-on' science activities so effective for student learning? Teach. Sci. J. Aust. Sci. Teach. Assoc. 2010, $56,7-10$.

10. Chen, S.; Chang, W.-H.; Lai, C.-H.; Tsai, C.-Y. A comparison of students' approaches to inquiry, conceptual learning, and attitudes in simulation-based and microcomputer-based laboratories. Sci. Educ. 2014, 98, 905-935. [CrossRef]

11. Goswami, U. Mental Capital and Wellbeing: Making the Most of Ourselves in the 21st Century: Learning Difficulties: Future Challenges; Government Office for Science: London, UK, 2008.

12. Tobin, K. Research on science laboratory activities: In pursuit of better questions and answers to improve learning. Sch. Sci. Math 1990, 90, 403-418. [CrossRef]

13. Barros, B.; Read, T.; Verdejo, M.F. Virtual collaborative experimentation: An approach combining remote and local labs. IEEE Trans. Educ. 2008, 51, 242-250. [CrossRef]

14. Kukulska-Hulme, A.; Beirne, E.; Conole, G.; Costello, E.; Coughlan, T.; Ferguson, R.; FitzGerald, E.; Gaved, M.; Herodotou, C.; Holmes, W.; et al. Innovating Pedagogy 2020: Open University Innovation Report 8; Open University: Milton Keynes, UK, 2020.

15. Idrissi, A.J.; Margoum, S.; Bendaoud, R.; Berrada, K. UC@MOOC's effectiveness by producing open educational resources. IJIMAI 2018, 5, 58-62. [CrossRef]

16. Idrissi, A.J.; Berrada, K.; Bendaoud, R.; Machwate, S.; Miraoui, A.; Burgos, D. Starting MOOCs in African University: The experience of Cadi Ayyad University, process, review, recommendations, and prospects. IEEE Access 2020, 8, 17477-17488. [CrossRef]

17. Idrissi, A.J.; Berrada, K.; Bendaoud, R.; El Kharki, K.; Machwate, S.; Miraoui, A. Cost Effective Open Educational Platform to Face the Challenge of Massification in Cadi Ayyad University. Iraqi J. Sci. 2021, 7-16. [CrossRef]

18. Zaatri, I.; El Kharki, K.; Bendaoud, R.; Berrada, K. The use of Open Educational Resources at Cadi Ayyad University: State of art review. In Proceedings of the 2019 7th International conference on ICT \& Accessibility (ICTA), Hammamet, Tunisia, 13-15 December 2019; pp. 1-4.

19. Zaatri, I.; Margoum, S.; Bendaoud, R.; El Malti, I.L.; Burgos, D.; Berrada, K. Open Educational Resources in Morocco. In Current State of Open Educational Resources in the "Belt and Road" Countries; Springer: Singapore, 2020; pp. 119-134.

20. Machwate, S.; Bendaoud, R.; Berrada, K. Media Coverage of Digital Resources in Audiovisual Format: Evaluation of Six Years of Application and Proposal of Development Paths. In Radical Solutions and eLearning; Springer: Singapore, 2020 ; pp. 167-182.

21. Berrada, K.; Ait Si Ahmad, H.; Margoum, S.; EL Kharki, K.; Machwate, S.; Bendaoud, R.; Burgos, D. From the Paper Textbook to the Online Screen: A Smart Strategy to Survive as an Online Learner. In Radical Solutions for Education in a Crisis Context; Springer: Singapore, 2021; pp. 191-205.

22. Ait Si Ahmad, H.; El Kharki, K.; Berrada, K. Agility of the Post COVID-19 Strategic Plan on Distance Learning at Cadi Ayyad University. An Opportunity Towards a Total Digital Transformation of the University. In Proceedings of the International Workshop on Higher Education Learning Methodologies and Technologies Online, Bari, Italy, 17-18 September 2020; pp. 199-213.

23. Cabedo, L.; Royo, M.; Moliner, L.; Guraya, T. University social responsibility towards engineering undergraduates: The effect of methodology on a service-learning experience. Sustainability 2018, 10, 1823. [CrossRef]

24. Zaturrahmi, Z.; Festiyed, F.; Ellizar, E. The Utilization of Virtual Laboratory in Learning: A Meta-Analysis. Indones. J. Sci. Math. Educ. 2020, 3, 228-236. [CrossRef]

25. Scanlon, E.; Morris, E.; Di Paolo, T.; Cooper, M. Contemporary approaches to learning science: Technologically-mediated practical work. Stud. Sci. Educ. 2002, 38, 73-114. [CrossRef]

26. Restivo, M.T.; Cardoso, A. Exploring Online Experimentation. Int. J. Online Eng. 2013, 4-6. Available online: https://onlinejournals.org/index.php/i-joe/article/view/3448/2902 (accessed on 15 July 2020). [CrossRef]

27. Hassan, H.; Martinez-Rubio, J.-M.; Perles, A.; Capella, J.-V.; Dominguez, C.; Albaladejo, J. Smartphone-based industrial informatics projects and laboratories. IEEE Trans. Ind. Inform. 2012, 9, 557-566. [CrossRef]

28. Kozma, R.B. Will media influence learning? Reframing the debate. Educ. Technol. Res. Dev. 1994, 42, 7-19. [CrossRef]

29. Guimaraes, E.G.; Cardozo, E.; Moraes, D.H.; Coelho, P.R. Design and implementation issues for modern remote laboratories. IEEE Trans. Learn. Technol. 2010, 4, 149-161. [CrossRef]

30. Wästberg, B.S.; Eriksson, T.; Karlsson, G.; Sunnerstam, M.; Axelsson, M.; Billger, M. Design considerations for virtual laboratories: A comparative study of two virtual laboratories for learning about gas solubility and colour appearance. Educ. Inf. Technol. 2019, 24, 2059-2080. [CrossRef]

31. Diwakar, S.; Kumar, D.; Radhamani, R.; Nizar, N.; Nair, B.; Sasidharakurup, H.; Achuthan, K. Role of ICT-enabled virtual laboratories in biotechnology education: Case studies on blended and remote learning. In Proceedings of the 2015 International Conference on Interactive Collaborative Learning (ICL), Firenze, Italy, 20-24 September 2015; pp. 915-921.

32. De La Torre, L.; Guinaldo, M.; Heradio, R.; Dormido, S. The ball and beam system: A case study of virtual and remote lab enhancement with moodle. IEEE Trans. Ind. Inform. 2015, 11, 934-945. [CrossRef] 
33. El Kharki, K.; Bensamka, F.; Berrada, K. Enhancing Practical Work in Physics Using Virtual Javascript Simulation and LMS Platform. In Radical Solutions and eLearning; Burgos, D., Ed.; Springer: Singapore, 2020; pp. 131-146.

34. El Kharki, K.; Bensamka, F.; Berrada, K.; El Hajjaji, K.; El Kbiach, M.L.; Bounab, L. Vers un laboratoire virtuel des TP en Sciences physiques: Cas du projet EXPERES. Int. J. Appl. Res. Technol. 2018, N¹. Available online: https://www.researchgate.net/ publication/330994513_Vers_un_laboratoire_virtuel_des_TP_en_Sciences_physiques_cas_du_projet_EXPERES (accessed on 1 October 2020).

35. United Nations Transforming Our World: The 2030 Agenda for Sustainable Development. Available online: https: / / sustainabledevelopment.un.org/post2015/transformingourworld (accessed on 1 February 2021).

36. Rieckmann, M. Education for Sustainable Development Goals: Learning Objectives; Unesco Publishing: Paris, France, 2017.

37. Burmeister, M.; Rauch, F.; Eilks, I. Education for Sustainable Development (ESD) and chemistry education. Chem. Educ. Res. Pract. 2012, 13, 59-68. [CrossRef]

38. Valderrama-Hernández, R.; Sánchez-Carracedo, F.; Alcántara Rubio, L.; Limón-Domínguez, D. Methodology to Analyze the Effectiveness of ESD in a Higher Degree in Education. A Case Study. Sustainability 2020, 12, 222. [CrossRef]

39. Bhardwaj, A. Importance of education in human life: A holistic approach. Int. J. Sci. Conscious. 2016, 2, 23-28.

40. Barth, M.; Burandt, S. Adding the "e-" to learning for sustainable development: Challenges and innovation. Sustainability 2013, 5, 2609-2622. [CrossRef]

41. Kanwar, A.; Kodhandaraman, B.; Umar, A. Toward sustainable open education resources: A perspective from the global south. Am. J. Distance Educ. 2010, 24, 65-80. [CrossRef]

42. Zaid, Y.A.; Alabi, A.O. Sustaining Open Educational Resources (OER) initiatives in Nigerian Universities. Open Learn. J. Open Distance e-Learn. 2020, 1-18. [CrossRef]

43. Bochicchio, M.A.; Longo, A.; Vaira, L.; Zappatore, M. Fostering online scientific experimentations in universities and high schools: The EDOC project. In Proceedings of the 2015 3rd Experiment International Conference (exp. at'15), Ponta Delgada, Portugal, 2-4 June 2015; pp. 337-342.

44. Zajko, K.; Bradač Hojnik, B. Social franchising model as a scaling strategy for ICT reuse: A case study of an international franchise. Sustainability 2018, 10, 3144. [CrossRef]

45. Paredes-Labra, J.; Siri, I.-M.; Oliveira, A. Preparing public pedagogies with ict: The case of pesticides and popular education in brazil. Sustainability 2018, 10, 3377. [CrossRef]

46. Gamage, K.A.A.; Wijesuriya, D.I.; Ekanayake, S.Y.; Rennie, A.E.W.; Lambert, C.G.; Gunawardhana, N. Online delivery of teaching and laboratory practices: Continuity of university programmes during COVID-19 pandemic. Educ. Sci. 2020, 10, 291. [CrossRef]

47. Samuelsen, D.A.H.; Graven, O.H. Remote laboratories in engineering education-an overview of implementation and feasability. In Proceedings of the 14th LACCEI International Multi-Conference for Engineering, Education and Technology, San José, Costa Rica, 20-22 July 2016.

48. Ouatik, F.; Raoufi, M.; Bouikhalene, B.; Skouri, M. The EOLES project remote labs across the Mediterranean: An example of a successful experience. In Proceedings of the 2017 International Conference on Smart Digital Environment, Rabat, Morocco, 21-23 July 2017; pp. 155-161.

49. Potkonjak, V.; Gardner, M.; Callaghan, V.; Mattila, P.; Guetl, C.; Petrović, V.M.; Jovanović, K. Virtual laboratories for education in science, technology, and engineering: A review. Comput. Educ. 2016, 95, 309-327. [CrossRef]

50. Román-Ibáñez, V.; Pujol-López, F.A.; Mora-Mora, H.; Pertegal-Felices, M.L.; Jimeno-Morenilla, A. A Low-Cost Immersive Virtual Reality System for Teaching Robotic Manipulators Programming. Sustainability 2018, 10, 1102. [CrossRef]

51. Cabero-Almenara, J.; Barroso-Osuna, J.; Llorente-Cejudo, C.; del Mar Fernández Martínez, M. Educational Uses of Augmented Reality (AR): Experiences in Educational Science. Sustainability 2019, 11, 4990. [CrossRef]

52. Calabuig-Moreno, F.; González-Serrano, M.H.; Fombona, J.; García-Tascón, M. The Emergence of Technology in Physical Education: A General Bibliometric Analysis with a Focus on Virtual and Augmented Reality. Sustainability 2020, $12,2728$. [CrossRef]

53. Merchant, Z.; Goetz, E.T.; Cifuentes, L.; Keeney-Kennicutt, W.; Davis, T.J. Effectiveness of virtual reality-based instruction on students' learning outcomes in K-12 and higher education: A meta-analysis. Comput. Educ. 2014, 70, 29-40. [CrossRef]

54. Shin, D.-H. The role of affordance in the experience of virtual reality learning: Technological and affective affordances in virtual reality. Telemat. Inform. 2017, 34, 1826-1836. [CrossRef]

55. Pirker, J.; Gutl, C.; Astatke, Y. Enhancing online and mobile experimentations using gamification strategies. In Proceedings of the 2015 3rd Experiment International Conference (exp. at'15), Ponta Delgada, Portugal, 2-4 June 2015; pp. $224-229$.

56. Raman, R.; Achuthan, K.; Nedungadi, P.; Diwakar, S.; Bose, R. The VLAB OER experience: Modeling potential-adopter student acceptance. IEEE Trans. Educ. 2014, 57, 235-241. [CrossRef]

57. Salmerón-Manzano, E.; Manzano-Agugliaro, F. The higher education sustainability through virtual laboratories: The Spanish University as case of study. Sustainability 2018, 10, 4040. [CrossRef]

58. Ma, J.; Nickerson, J.V. Hands-on, simulated, and remote laboratories: A comparative literature review. ACM Comput. Surv. 2006, 38, 7. [CrossRef]

59. Brinson, J.R. Learning outcome achievement in non-traditional (virtual and remote) versus traditional (hands-on) laboratories: A review of the empirical research. Comput. Educ. 2015, 87, 218-237. [CrossRef] 
60. Chao, J.; Chiu, J.L.; DeJaegher, C.J.; Pan, E.A. Sensor-augmented virtual labs: Using physical interactions with science simulations to promote understanding of gas behavior. J. Sci. Educ. Technol. 2016, 25, 16-33. [CrossRef]

61. Son, J.Y. Comparing physical, virtual, and hybrid flipped labs for general education biology. Online Learn. 2016, 20, 228-243. [CrossRef]

62. Achuthan, K.; Francis, S.P.; Diwakar, S. Augmented reflective learning and knowledge retention perceived among students in classrooms involving virtual laboratories. Educ. Inf. Technol. 2017, 22, 2825-2855. [CrossRef]

63. Achuthan, K.; Kolil, V.K.; Diwakar, S. Using virtual laboratories in chemistry classrooms as interactive tools towards modifying alternate conceptions in molecular symmetry. Educ. Inf. Technol. 2018, 23, 2499-2515. [CrossRef]

64. Whitworth, K.; Leupen, S.; Rakes, C.; Bustos, M. Interactive computer simulations as pedagogical tools in biology labs. CBE-Life Sci. Educ. 2018, 17, ar46. [CrossRef] [PubMed]

65. Moosvi, F.; Reinsberg, S.; Rieger, G. Can a hands-on physics project lab be delivered effectively as a distance lab? Int. Rev. Res. Open Distrib. Learn. 2019, 20. [CrossRef]

66. Billah, A.; Widiyatmoko, A. The Development of Virtual Laboratory Learning Media for The Physical Optics Subject. Development 2018. [CrossRef]

67. Lestari, D.P. Supahar Students and teachers' necessity toward virtual laboratory as an instructional media of 21st century science learning. J. Phys. Conf. Ser. 2020, 1440, 12091. [CrossRef]

68. Zhao, Y.; Flanagan, E.; Abbasi, H.; Black, K.; Wang, X.; Cardona, A. Development of a Virtual Lab in Assistance of a Fluid Mechanics Laboratory Instruction. In Proceedings of the ASME 2019 International Mechanical Engineering Congress and Exposition, Salt Lake City, UT, USA, 11-14 November 2019.

69. Gunawan, G.; Suranti, N.M.Y.; Nisrina, N.; Ekasari, R.R. The Effect of Virtual Labs Toward Students' Understanding of Physics Based on Gender. Adv. Soc. Sci. Educ. Humanit. Res. 2018, 173, 128-131.

70. Gunawan, G.; Harjono, A.; Sahidu, H.; Herayanti, L.; Suranti, N.M.Y.; Yahya, F. Using virtual laboratory to improve pre-service physics teachers' creativity and problem-solving skills on thermodynamics concept. J. Phys. Conf. Ser. 2019, 1280, 52038. [CrossRef]

71. Gunawan, G.; Harjono, A.; Sahidu, H.; Herayanti, L. Virtual laboratory to improve students' problem-solving skills on electricity concept. J. Pendidik. IPA Indones. 2017, 6, 257-264. [CrossRef]

72. Gunawan; Harjono, A.; Sahidu, H.; Nisrina. Improving students' creativity using cooperative learning with virtual media on static fluida concept. J. Phys. Conf. Ser. 2018, 1006, 12016. [CrossRef]

73. Jiménez, C.F.; Guadaño, L.H.; Muñoz, F.P. Virtual Labs: A Complement for Traditional Laboratories. Available online: http: / / oa.upm.es/41724/1/INVE_MEM_2014_219761.pdf (accessed on 10 March 2021).

74. Kapilan, N.; Vidhya, P.; Gao, X.-Z. Virtual Laboratory: A Boon to the Mechanical Engineering Education During Covid-19 Pandemic. High. Educ. Future 2020. [CrossRef]

75. García-Vela, M.; Zambrano, J.L.; Falquez, D.A.; Pincay-Musso, W.; Duque, K.B.; Zumba, N.V.; Barcia, M.B.; Méndez, J.I.; Valverde, P.E.; Romero-Crespo, P.L.; et al. Management of virtual laboratory experiments in the geosciences field in the time of COVID-19 pandemic. In Proceedings of the ICERI2020 Conference, Seville, Spain, 9-10 November 2020; Volume 9, p. 10.

76. Radhamani, R.; Sasidharakurup, H.; Kumar, D.; Nizar, N.; Nair, B.; Achuthan, K.; Diwakar, S. Explicit interactions by users form a critical element in virtual labs aiding enhanced education-A case study from biotechnology virtual labs. In Proceedings of the 2014 IEEE Sixth International Conference on Technology for Education, Amritapuri, India, 18-21 December $2014 ;$ pp. 110-115.

77. Gratch, J.; Kelly, J.; Bradley, C. Science simulations: What do they contribute to student learning? In Proceedings of the Society for Information Technology \& Teacher Education International Conference, San Antonio, TX, USA, 26 March 2007; pp. $3422-3425$.

78. Lowe, R.K. Animation and learning: Selective processing of information in dynamic graphics. Learn. Instr. 2003, 13, 157-176. [CrossRef]

79. Heradio, R.; de la Torre, L.; Galan, D.; Cabrerizo, F.J.; Herrera-Viedma, E.; Dormido, S. Virtual and remote labs in education: A bibliometric analysis. Comput. Educ. 2016, 98, 14-38. [CrossRef]

80. Sarabando, C.; Cravino, J.P.; Soares, A.A. Contribution of a computer simulation to students' learning of the physics concepts of weight and mass. Procedia Technol. 2014, 13, 112-121. [CrossRef]

81. Esquembre, F. Easy Java Simulations: A software tool to create scientific simulations in Java. Comput. Phys. Commun. 2004, 156, 199-204. [CrossRef]

82. Campos, N.; Nogal, M.; Caliz, C.; Juan, A.A. Simulation-based education involving online and on-campus models in different European universities. Int. J. Educ. Technol. High. Educ. 2020, 17, 1-15. [CrossRef]

83. Lyons, J. Learning with technology: Theoretical foundations underpinning simulations in higher education. In Proceedings of the ASCILITE 2012 Future Challenges, Sustainable Futures, Wellington, New Zealand, 25-28 November 2012; pp. 582-586.

84. Stančić, H.; Seljan, S.; Cetinić, A.; Sanković, D. Simulation models in education. In Proceedings of the INFuture2007 “Digital Information Heritage", Zagreb, Croatia, 7-9 November 2007; pp. 469-481.

85. Costantino, F.; Di Gravio, G.; Shaban, A.; Tronci, M. A simulation based game approach for teaching operations management topics. In Proceedings of the the 2012 Winter Simulation Conference (WSC), Berlin, Germany, 9-12 December 2012; pp. 1-12.

86. Martin, D.; McEvoy, B. Business simulations: A balanced approach to tourism education. Int. J. Contemp. Hosp. Manag. 2003, 15, 336-339. [CrossRef]

87. Molenda, M. In search of the elusive ADDIE model. Perform. Improv. 2003, 42, 34-37. [CrossRef] 
88. Christian, W.; Esquembre, F. Modeling physics with easy Java simulations. Phys. Teach. 2007, 45, 475-480. [CrossRef]

89. Moodle Open-Source Learning Platform-Moodle. Available online: https:/ / moodle.org/ (accessed on 15 October 2020).

90. Cugler, D.C.; Yaguinuma, C.A.; Santos, M.T.P. WOntoVLab: A virtual laboratory authorship process based on workflow and ontologies. In Proceedings of the 2010 10th IEEE International Conference on Advanced Learning Technologies, Sousse, Tunisia, 5-7 July 2010; pp. 690-694.

91. Redel-Macías, M.D.; Pinzi, S.; Martínez-Jiménez, M.P.; Dorado, G.; Dorado, M.P. Virtual laboratory on biomass for energy generation. J. Clean. Prod. 2016, 112, 3842-3851. [CrossRef]

92. Azma, F.; Shima, K.-M.; Zahra, K.; Maziar, R.; Somayeh, R.; Mohammadi, H.R. Association between generation gap in interest, familiarity and application of information and communication technology. Soc. Sci. 2016, 11, 1956-1961.

93. Hoosen, S.; Moore, D.; Butcher, N. Open Educational Resources (OER) Guide for Students in Post-Secondary and Higher Education; Commonwealth of Learning: Burnaby, BC, Canada, 2016; ISBN 978-1-894975-78-0.

94. Kituyi, G.; Tusubira, I. A framework for the integration of e-learning in higher education institutions in developing countries. Int. J. Educ. Dev. Using ICT 2013, 9, 19-36.

95. Dillenbourg, P.; Schneider, D.; Synteta, P. Virtual learning environments. In Proceedings of the 3rd Hellenic Conference "Information \& Communication Technologies in Education", Rhodes, Greece, 26-29 September 2002; pp. 3-18.

96. Kolb, D.A. Experiential Learning: Experience as the Source of Learning and Development; FT Press: Englewood Cliffs, NJ, USA, 2014.

97. Rutten, N.; Van Joolingen, W.R.; Van Der Veen, J.T. The learning effects of computer simulations in science education. Comput. Educ. 2012, 58, 136-153. [CrossRef]

98. Rowe, R.J.; Koban, L.; Davidoff, A.J.; Thompson, K.H. Efficacy of online laboratory science courses. J. Form. Des. Learn. 2018, 2, 56-67. [CrossRef]

99. Coenders, F.; Gomes, N.; Sayegh, R.; Kinyanjui, I.; Noutahi, A.; Madu, N. Class experiences with inquiry learning spaces in go-lab in African secondary schools. Afr. J. Teach. Educ. 2020, 9, 1-22. [CrossRef]

100. Estriegana, R.; Medina-Merodio, J.-A.; Barchino, R. Student acceptance of virtual laboratory and practical work: An extension of the technology acceptance model. Comput. Educ. 2019, 135, 1-14. [CrossRef]

101. Kapici, H.O.; Akcay, H.; de Jong, T. Using hands-on and virtual laboratories alone or together-Which works better for acquiring knowledge and skills? J. Sci. Educ. Technol. 2019, 28, 231-250. [CrossRef]

102. Wang, T.-L.; Tseng, Y.-K. The comparative effectiveness of physical, virtual, and virtual-physical manipulatives on third-grade students' science achievement and conceptual understanding of evaporation and condensation. Int. J. Sci. Math. Educ. 2018, 16, 203-219. [CrossRef]

103. Zacharia, Z.C.; Michael, M. Using physical and virtual manipulatives to improve primary school students' understanding of concepts of electric circuits. In New Developments in Science and Technology Education; Springer: Cham, Switzerland, 2016; pp. 125-140. 